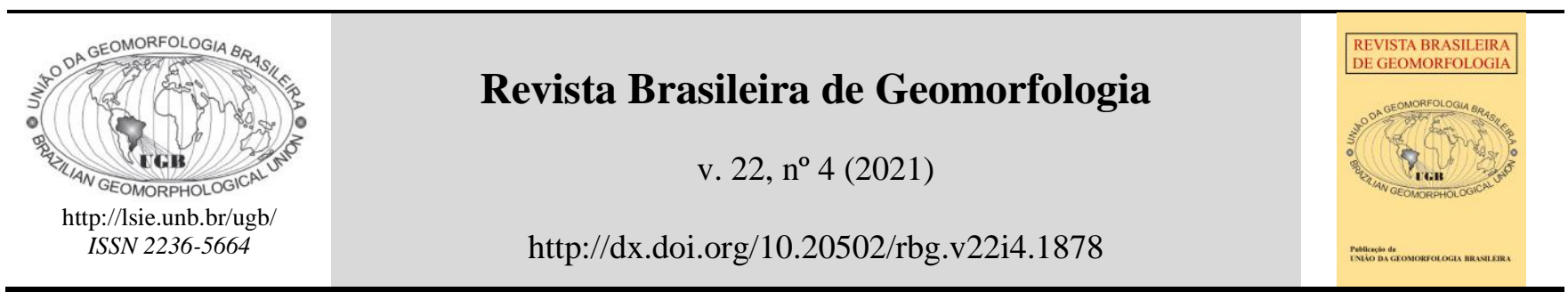

Artigo de Pesquisa

\title{
Sequências deposicionais fluviais e evolução geomorfológica da bacia do Rio Paraúna - Serra do Espinhaço Meridional, Sudeste do Brasil
}

\section{Fluvial depositional sequences and geomorphological evolution of the Parauna river basin - Meridional Espinhaço range, Southeastern of Brazil}

\author{
Alex de Carvalho1, Antônio Pereira Magalhães Junior ${ }^{2}$ \\ 1 Instituto Federal de Minas Gerais, Coordenadoria da Área de Geografia, Ouro Preto, Brasil. E-mail. \\ alex.carvalho@ifmg.edu.br \\ ORCID: http://orcid.org/0000-0001-6525-3170 \\ 2 Universidade Federal de Minas Gerais, Departamento de Geografia, Belo Horizonte, Brasil. E-mail. \\ magalhaesufmg@yahoo.com.br \\ ORCID: http://orcid.org/0000-0002-5327-3729
}

Recebido: 05/03/2020; Aceito: 08/07/21; Publicado: 01/10/2021

\begin{abstract}
Resumo: A identificação de registros de mudanças na dinâmica hidrossedimentar ao longo do tempo permite verificar possíveis alterações da estabilidade de sistemas fluviais e discutir suas implicações na evolução geomorfológica. Este artigo discute a contribuição dos processos fluviais na configuração geomorfológica da bacia do rio Paraúna, ao longo do Pleistoceno Superior/Holoceno. Realizaram-se as seguintes etapas metodológicas: reunião de informações da área estudada; a identificação, mapeamento e caracterização de níveis e sequências deposicionais fluviais; e a datação de sedimentos fluviais pela Luminescência Opticamente Estimulada (LOE). Baseando-se na topografia e na resistência litológica, pode-se identificar dois compartimentos geomorfológicos: Superfícies Elevadas (SE) e Depressão de Gouveia (DG). A dinâmica fluvial é condicionada pelo nível de base regional (rio Paraúna) na DG e pelos níveis de base locais controlados por quartzitos (Supergrupo Espinhaço) nas SE. Frequentemente, as médias/altas vertentes possuem níveis de seixos escalonados e os fundos de vale colmatados possuem níveis arenosos embutidos e/ou encaixados. Na DG, a estabilização do nível de base condicionou a configuração dos fundos de vale, favorecendo a redução da incisão fluvial, o encouraçamento das calhas e a regularização dos perfis longitudinais. Nas SE, a litologia e aspectos locais das bacias e dos canais explicam a diversidade de configurações de vales.
\end{abstract}

Palavras-chave: Geomorfologia fluvial; Níveis deposicionais; Terraços fluviais; Quaternário continental.

\begin{abstract}
The identification of records of changes in hydro-sedimentary dynamics over time allows the verification of possible changes in the stability of river systems as well as to discuss their implications for geomorphological evolution. This article discusses the contribution of river processes on the geomorphological configuration of the Paraúna River basin, during the Upper Pleistocene/Holocene. The following methodological steps were carried out: information gathering from the studied area; identification, mapping and characterization of fluvial depositional levels and sequences; dating of fluvial sediments using Optically Stimulated Luminescence (OSL). Based on topography and lithological resistance, two geomorphological compartments could be identified: Elevated Surfaces (ES) and Gouveia Depression (GD). The fluvial dynamic is conditioned by the regional base level (Paraúna river) in the GD and by the local base levels controlled by quartzites (Supergroup Espinhaço) in the SE. Often, the medium/high slopes have staggered pebble levels and the alluvial bottom valleys have been found nested or cut-in-bedrocks. In the GD, the stabilization of the base level conditioned the configuration of the bottom
\end{abstract}


valleys, favoring the reduction of the fluvial incision, the bed armoring and the regularization of the longitudinal profiles. In the ES, the lithology and local aspects of the basins and channels explain the diversity of valley configurations.

Keywords: Fluvial Geomorphology; Depositional levels; Fluvial terraces; Continental Quaternary.

\section{Introdução}

A investigação das relações entre a dinâmica fluvial e as formas de relevo em uma bacia hidrográfica ou de um vale fluvial requer o cuidado de identificar e selecionar os elementos que deverão compor o estudo. A forma da bacia e a tipologia da rede de drenagem, por exemplo, podem passar longos períodos se ajustando às condições ambientais, promovendo alterações na posição dos interflúvios ou promovendo a reorganização/rearranjo da rede de drenagem (PRINCE; SPOTILA; HENIKA, 2011; HASBARGEN; PAOLA, 2000; REINHARDT; ELLIS, 2015; GOREN et al., 2014; WILLETT et al., 2014).

A identificação de registros de mudanças na dinâmica de processos hidrossedimentares ao longo do tempo constitui um dos principais meios da verificação de possíveis alterações da estabilidade de sistemas fluviais. Os depósitos sedimentares aluviais se destacam por sinalizarem as influências dos condicionantes geomorfológicos na evolução e configuração do relevo. Assim, é possível reconstituir aspectos importantes da evolução dos sistemas hidrográficos, como a capacidade e competência de transporte, áreas fontes de sedimentos, distâncias de deslocamento de clastos e características dos ambientes paleodeposicionais (CHRISTOFOLETTI, 1980; HACK, 1960; MAGALHÃES JUNIOR; BARROS, 2020). A reconstituição do papel dos processos fluviais na evolução do relevo deve buscar integrar aspectos geomorfológicos, sedimentológicos, e estratigráficos, o que contribui para a ampliação do conhecimento sobre o Quaternário continental (TORRES; MARQUES NETO; MENEZES, 2012).

Nas últimas décadas, diversos estudos foram realizados na Serra do Espinhaço Meridional (SEM), destacando-se a área drenada pela rede hidrográfica do rio Paraúna. As pesquisas recentes sugerem que a região estaria passando por um período de instabilidade tectônica responsável por desajustes nos sistemas fluviais. São apresentados como indícios as alterações na cobertura pedológica (CRUZ et al., 2006; MENEZES et al., 2006; ÁVILA; CARVALHO, 2012; MESSIAS et al., 2013), e o encaixamento da rede de drenagem (SAADI; VALADÃO, 1987; MAGALHÃES JUNIOR et al., 1992; BUENO; TRINDADE; MAGALHÃES JUNIOR, 1997; ROCHA et al., 2010; MESSIAS; MAGALHÃES JUNIOR, 2014; OLIVEIRA, 2017; COTA; MAGALHÃES JUNIOR; BARROS, 2018).

Este trabalho parte deste cenário em que a evolução do relevo em uma bacia hidrográfica tem forte relação com a evolução da própria rede fluvial e que os registros deposicionais fluviais e outras características morfológicas podem subsidiar a interpretação da morfogênese regional, sobretudo no intervalo de tempo associado aos respectivos depósitos sedimentares fluviais. Assim, esse trabalho busca discutir a contribuição dos processos fluviais na configuração geomorfológica da bacia do rio Paraúna, na SEM, ao longo do Pleistoceno Superior e Holoceno.

\section{2. Área de Estudo}

O rio Paraúna é um tributário do baixo curso do Rio das Velhas. Sua bacia hidrográfica se divide entre dois contextos geomorfológicos. Uma parte drena uma faixa prolongada de sentido norte-sul, composta principalmente pela escarpa oeste da SEM e uma faixa da depressão onde afloram as rochas do Grupo Bambuí. A outra parte da bacia corresponde à área drenada pelo Rio Paraúna e seus tributários nas superfícies mais elevadas da SEM, onde afloram as rochas do Supergrupo Espinhaço e do Complexo Gouveia (ROCHA et al., 2008).

A área investigada corresponde à bacia do Paraúna desde suas nascentes, a leste, até a confluência com o Córrego da Contagem, a oeste, no contexto geomorfológico da SEM (Figura 1). A área de estudo integra a Cadeia do Espinhaço, um conjunto de terras altas que formam um importante divisor hidrográfico entre as bacias do rio São Francisco, a oeste, e as bacias dos rios Doce e Jequitinhonha, a leste (VALADÃO, 2009). A unidade de estudo fundamental nesta pesquisa é a parte da SEM drenada pela bacia do Paraúna. No entanto, para subsidiar as discussões a respeito da evolução geomorfológica da região, algumas subunidades foram definidas: os vales fluviais do rio Paraúna e de alguns afluentes - os vales dos ribeirões do Chiqueiro, da Areia, Datas, Congonhas e Palmital e dos córregos Rio Grande, do Tigre, da Sepultura e da Contagem. 


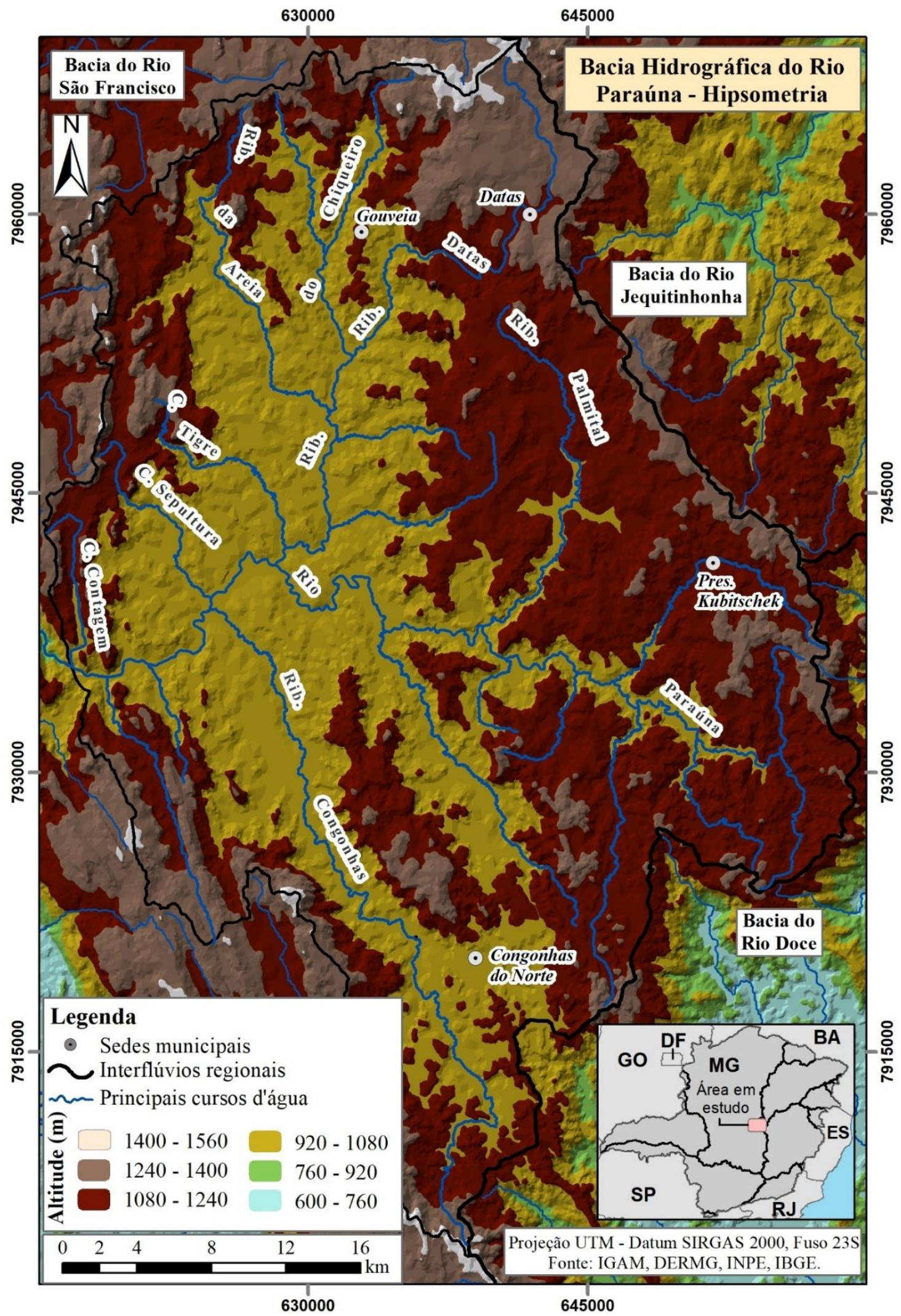

Figura 1: Localização da área de estudo, principais vias de acesso pavimentadas e hipsometria.

A SEM é um dos compartimentos tectônicos da Faixa Araçuaí, cujos planos exibem direções N-S e mergulhos que variam de moderados a altos, margeia, a leste, o Cráton do São Francisco. A unidade é composta por rochas arqueanas e paleoproterozoicas do embasamento, rochas supracrustais dos supergrupos Espinhaço e São Francisco e intrusões máficas pós-Espinhaço (CORDEIRO et al., 2008; ALKMIN et al., 2007). A região é composta essencialmente por litologias do Supergrupo Espinhaço, marcado por um complexo quadro litoestrutural. 
Destacam-se rochas quartzíticas, filíticas, conglomeráticas e vulcânicas de caráter básico e ácido (ALMEIDAABREU, 1995). A oeste do cinturão de cavalgamentos, ocorrem as rochas metassedimentares neoproterozoicas do Grupo Bambuí. Na porção leste predominam os granitos, gnaisses e granitoides arqueanos do embasamento cristalino (GROSSI-SADI et al., 1997) - Figura 2.

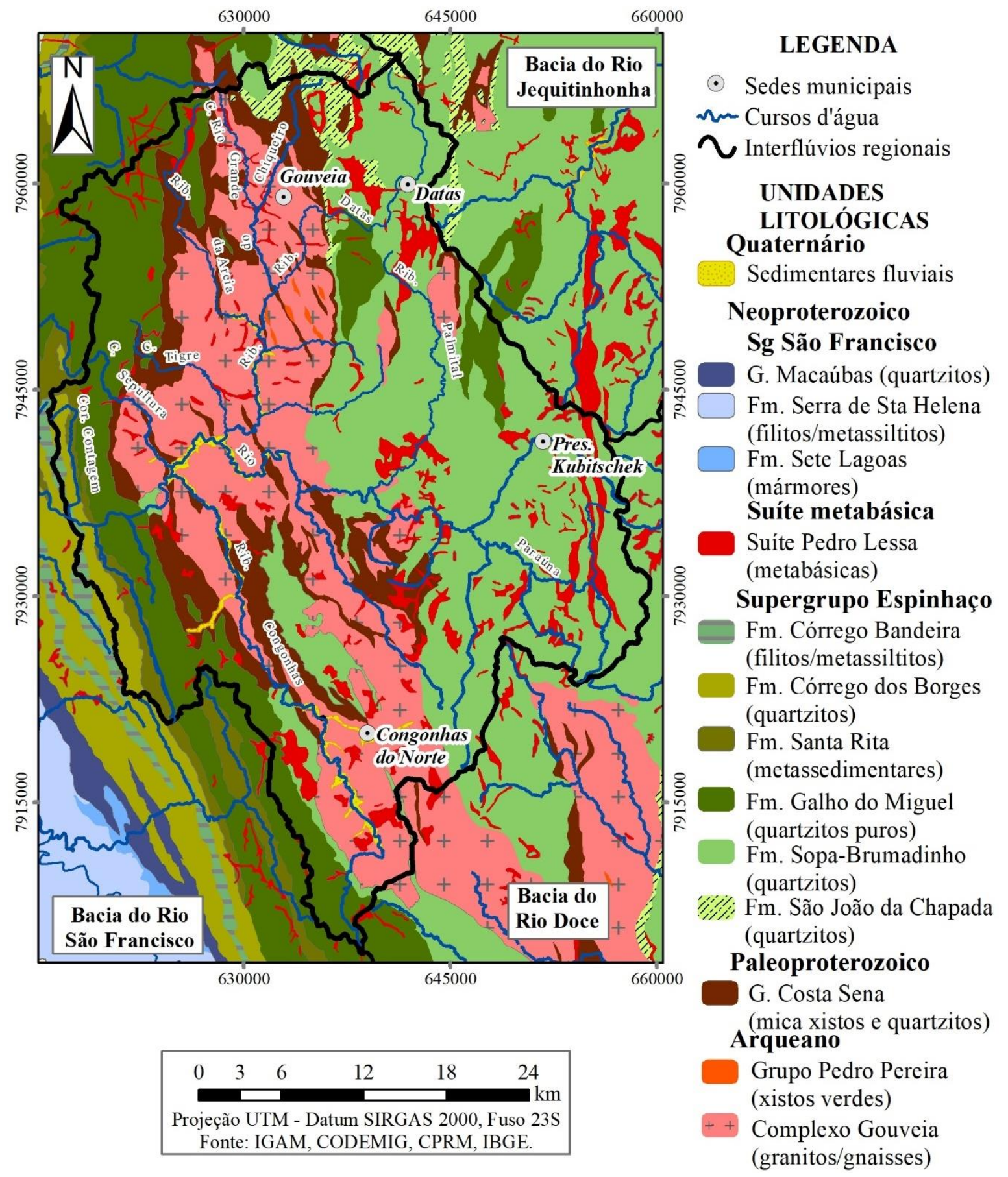

Figura 2: Quadro geológico regional e principais unidades litológicas.

A SEM é composta por um sistema de falhas inversas ou de empurrão e zonas de cisalhamento dúctil, com orientação N-S. Predominam falhas de empurrão e dobras com orientação preferencial N-S, associadas a um encurtamento geral de sentido E-W (KNAUER, 2007; ALKMIN et al., 2007). As principais estruturas regionais são os empurrões e dobras com vergência para oeste. No contato entre o Cráton do São Francisco e a Serra do Espinhaço, observa-se uma feição morfotectônica típica de front de cavalgamento, que separa o cráton do dobramento. Na borda leste, um conjunto de falhas, compõem o cinturão de cavalgamentos na região próxima à zona proximal da colisão continental que edificou o Orógeno Espinhaço (SAADI, 1995). 
Em Minas Gerais, a SEM pode ser considerada um planalto, direção geral N-S e convexidade orientada para oeste (ALMEIDA-ABREU; RENGER, 2002; SAADI, 1995). O alinhamento N-S reflete uma série de linhas de cristas descontínuas, de padrão sub-ortogonal, de direções NE-SW e NW-SE. A altitude média é de 1.250 m, destacandose o ponto mais elevado no município de Serro (Pico do Itambé - $2.062 \mathrm{~m}$ ) (NEVES; ALMEIDA-ABREU; FRAGA, 2005; SAADI, 1995). A Serra tem um comprimento de 300 quilômetros e aproximadamente 3,5 milhões de hectares (SILVA; PEDREIRA; ALMEIDA-ABREU, 2005).

O clima da SEM é influenciado pelo fator orográfico, notando-se um significativo aumento da temperatura média anual nas zonas externas da Serra. O clima é caracterizado como mesotérmico, Cwb segundo a classificação de Koppen, com verões brandos e úmidos (outubro a abril), invernos mais frescos e secos (junho a agosto) e curtas transições nos meses de maio e setembro. A precipitação média anual varia entre $1.250 \mathrm{~mm}$ e $1.550 \mathrm{~mm}$, enquanto a temperatura média anual varia entre $18^{\circ}$ e $19^{\circ} \mathrm{C}$. No verão, as temperaturas alcançam $35^{\circ} \mathrm{C}$, enquanto no inverno chegam a $4^{\circ} \mathrm{C}$ (NEVES; ALMEIDA-ABREU; FRAGA, 2005).

Nas áreas elevadas, associadas aos quartzitos, os solos são predominantemente arenosos e rasos, predominando Neossolos Litólicos, Neossolos Quartzarênicos e Organossolos Mésicos, considerados sem aptidão agrícola. Neles, desenvolvem-se campo rupestre, campo limpo, cerrado rupestre e campo cerrado (SILVA, 2005). Nas áreas deprimidas, com superfícies mais planas, a saturação hídrica, a elevada acidez e outras condições favorecem o acúmulo de matéria orgânica e a formação de Organossolos e de turfeiras (BENITES et al., 2007, 2003; HORÁK et al., 2011; SILVA et al., 2008). A umidade excessiva, as baixas temperaturas e os baixos pH e níveis de nutrientes contribuem para a inibição da atividade microbiológica, reduzindo as taxas de decomposição de matéria orgânica. Essas condições favorecem a humificação e mineralização da matéria orgânica, formando estruturas complexas, enriquecidos de carbono fixo e mais difíceis de serem destruídos (PONTEVEDRA-POMBAL; MARTINEZ CORTIZAS, 2004; PEREIRA; ANJOS; VALLADARES, 2005).

Nas planícies de inundação e em ambientes fluviais marginais predominam Gleissolos e Neossolos Flúvicos. Também são identificados Nitossolos, Argissolos e Latossolos, que possuem moderada aptidão agrícola e são muito vulneráveis aos processos erosivos. A vegetação dessas áreas é composta por matas ciliares ou campos com espécies adaptadas à saturação hídrica. Também são identificados fragmentos de floresta estacional e de cerradão. Alguns Latossolos e Cambissolos apresentam maior aptidão agrícola e correspondem às áreas mais ocupadas pelas atividades antrópicas (SILVA, 2005).

\section{Materiais e Métodos}

A pesquisa foi realizada com base na reunião de informações preliminares sobre a área de estudo, na identificação, mapeamento e caracterização de níveis e sequências deposicionais fluviais e na datação de sedimentos de depósitos fluviais chave por Luminescência Opticamente Estimulada (LOE).

Inicialmente, realizou-se a revisão de literatura e a reunião da base de dados cartográficos (1:100.000 e 1:50.000). Foram selecionadas bases cartográficas de topografia (SRTM - Topodata/INPE), hidrografia (IGAM, 2010 - 1:50.000), litologia e estrutura (CPRM; CODEMIG - 1:100.000), rodovias (DER - 1:100.000), além de cartas topográficas digitais do IBGE $(1975,1979$ - 1:100.000 e 1:50.000).

Em seguida foram coletadas informações em campo, partindo da seleção de trechos do rio Paraúna e de seus principais afluentes (os de maior ordem hierárquica) com acesso por meio de estradas de terra ou vias pavimentadas. Devido à extensão dos vales fluviais e às condições de vegetação e de topografia, foi inviável percorrer trechos a pé. A partir das observações de campo, foram identificados, caracterizados e mapeados os níveis e as sequências deposicionais fluviais dos vales. Utilizando fichas de campo e registrando as principais informações: tipologia dos depósitos - escalonado, embutido, encaixado; contexto espacial ao longo do vale - cota, desnível em relação à lâmina d'água do curso d'água atual e a distribuição; espessura dos depósitos, composição granulométrica, organização das fácies sedimentares, tipo de contatos entre fácies, presença de estruturas primárias e outras. Os pontos descritos foram georreferenciados com um GPS, auxiliando a representação da organização transversal e longitudinal dos níveis e sequências. Foram elaborados perfis estratigráficos síntese, reunindo as características mais relevantes dos níveis deposicionais, conforme Magalhães Junior (1993).

Foram coletadas 24 amostras de sedimentos arenosos e quartzosos para a datação por LOE, priorizando depósitos em fundo de vale (Quadro 1). As amostras estão distribuídas da seguinte forma entre os vales: 4 - Rio Grande; 3 - Chiqueiro; 2 -Areia; 2 - Datas; 4 - Congonhas; 4 - Paraúna; 2 - Palmital; 1 - Contagem; 2 - Sepultura. 
Quadro 1: coordenadas geográficas e nível deposicional datados por LOE. PI - planície de inundação; N1 e N2 níveis deposicionais.

\begin{tabular}{|c|c|c|c|c|}
\hline CURSO FLUVIAL & N. DA AMOSTRA & NÍVEL & LONGITUDE & LATITUDE \\
\hline \multirow{4}{*}{ Paraúna } & D01 & PI & $43^{\circ} 39^{\prime} 8,959^{\prime \prime} \mathrm{W}$ & $18^{\circ} 39^{\prime} 52,389^{\prime \prime} \mathrm{S}$ \\
\hline & D02 & N1 & $43^{\circ} 39^{\prime} 8,959^{\prime \prime} \mathrm{W}$ & $18^{\circ} 39^{\prime} 52,389^{\prime \prime} \mathrm{S}$ \\
\hline & D03 & N2 & $43^{\circ} 43^{\prime} 56,443^{\prime \prime} \mathrm{W}$ & $18^{\circ} 37^{\prime} 31,097^{\prime \prime} \mathrm{S}$ \\
\hline & D04 & PI & $43^{\circ} 45^{\prime} 10,729^{\prime \prime} \mathrm{W}$ & $18^{\circ} 38^{\prime} 8,723^{\prime \prime} \mathrm{S}$ \\
\hline \multirow{4}{*}{ Congonhas } & D05 & PI & $43^{\circ} 40^{\prime} 52,229 " \mathrm{~W}$ & $18^{o} 53^{\prime} 10,192$ " S \\
\hline & D06 & $\mathrm{N} 2$ & $43^{\circ} 45^{\prime} 6,106^{\prime \prime} \mathrm{W}$ & $18^{\circ} 45^{\prime} 21,743^{\prime \prime} \mathrm{S}$ \\
\hline & D07 & N2 & $43^{\circ} 47^{\prime} 32,938^{\prime \prime} \mathrm{W}$ & $18^{\circ} 39^{\prime} 21,453^{\prime \prime} \mathrm{S}$ \\
\hline & D08 & PI & $43^{\circ} 45^{\prime} 14,681^{\prime \prime} \mathrm{W}$ & $18^{\circ} 45^{\prime} 28,469^{\prime \prime} \mathrm{S}$ \\
\hline \multirow{2}{*}{ Palmital } & D09 & N1 & $43^{\circ} 39^{\prime} 41,131^{\prime \prime} \mathrm{W}$ & $18^{\circ} 30^{\prime} 30,016^{\prime \prime} \mathrm{S}$ \\
\hline & D10 & N2 & $43^{\text {o }} 40^{\prime} 4,493^{\prime \prime} \mathrm{W}$ & $18^{\circ} 30^{\prime} 19,479 " \mathrm{~S}$ \\
\hline Contagem & D11 & N1 & $43^{\circ} 53^{\prime} 14,569^{\prime \prime} \mathrm{W}$ & $18^{\circ} 36^{\prime} 34,685^{\prime \prime} \mathrm{S}$ \\
\hline \multirow{2}{*}{ Sepultura } & D12 & N1 & $43^{\circ} 49^{\prime} 56,246^{\prime \prime} \mathrm{W}$ & $18^{\circ} 36^{\prime} 27,008^{\prime \prime} \mathrm{S}$ \\
\hline & D13 & N2 & $43^{\circ} 49^{\prime} 56,246^{\prime \prime} \mathrm{W}$ & $18^{\circ} 36^{\prime} 27,008^{\prime \prime} \mathrm{S}$ \\
\hline \multirow{3}{*}{ Chiqueiro } & D14 & N1 & $43^{\circ} 43^{\prime} 58,828^{\prime \prime} \mathrm{W}$ & $18^{\circ} 24^{\prime} 29,614^{\prime \prime}$ S \\
\hline & D15 & N2 & $43^{\circ} 43^{\prime} 58,828^{\prime \prime} \mathrm{W}$ & $18^{\text {o } 24^{\prime} 29,614^{\prime \prime} \mathrm{S}}$ \\
\hline & D16 & N3 & $43^{\circ} 43^{\prime} 58,828^{\prime \prime} \mathrm{W}$ & $18^{\circ} 24^{\prime} 29,614^{\prime \prime} \mathrm{S}$ \\
\hline \multirow{4}{*}{ Rio Grande } & D17 & PI & $43^{\circ} 46^{\prime} 4,329^{\prime \prime} \mathrm{W}$ & $18^{\text {o }} 25^{\prime} 52,821^{\prime \prime} \mathrm{S}$ \\
\hline & D18 & N1 & $43^{\circ} 46^{\prime} 4,329^{\prime \prime} \mathrm{W}$ & $18^{\circ} 25^{\prime} 52,821^{\prime \prime} \mathrm{S}$ \\
\hline & D19 & N1 & $43^{\circ} 46^{\prime} 15,029^{\prime \prime} \mathrm{W}$ & $18^{o} 25^{\prime} 36,991^{\prime \prime} \mathrm{S}$ \\
\hline & D20 & N2 & $43^{\circ} 46^{\prime} 4,329^{\prime \prime} \mathrm{W}$ & $18^{\circ} 25^{\prime} 52,821^{\prime \prime} \mathrm{S}$ \\
\hline \multirow{2}{*}{ Areia } & D21 & PI & $43^{\circ} 47^{\prime} 27,232^{\prime \prime} \mathrm{W}$ & $18^{\mathrm{o}} 30^{\prime} 24,562^{\prime \prime} \mathrm{S}$ \\
\hline & D22 & $\mathrm{N} 2$ & $43^{\circ} 47^{\prime} 27,232^{\prime \prime} \mathrm{W}$ & $18^{\text {o }} 30^{\prime} 24,562^{\prime \prime} \mathrm{S}$ \\
\hline \multirow{2}{*}{ Datas (alto curso) } & D23 & PI & $43^{\circ} 39^{\prime} 11,502^{\prime \prime} \mathrm{W}$ & $18^{\circ} 26^{\prime} 39,838^{\prime \prime} \mathrm{S}$ \\
\hline & D24 & N2 & $43^{\circ} 39^{\prime} 1,195^{\prime \prime} \mathrm{W}$ & $18^{\circ} 26^{\prime} 48,699^{\prime \prime} \mathrm{S}$ \\
\hline
\end{tabular}

As coletas de sedimentos ocorreram sempre na base dos depósitos, evitando-se as fácies de seixos. A profundidade de coleta variou de acordo com a espessura de cada depósito e objetivou a identificação da fase inicial de formação da respectiva sequência deposicional. Foram inseridos tubos de PVC de $5 \mathrm{~mm}$ de diâmetro e $30 \mathrm{~cm}$ de comprimento, evitando a exposição das amostras à radiação solar. Os tubos, previamente identificados, foram inseridos horizontalmente por percussão nos sedimentos utilizando uma marreta de borracha, conforme procedimentos descritos por Sallun et al. (2007). Posteriormente, as amostras foram enviadas ao Laboratório Datação, Comércio e Prestação de Serviços Ltda. (LVD), em São Paulo, onde passaram por procedimentos padronizados para a obtenção das idades.

No laboratório, os tubos foram abertos e os sedimentos tratados em ambiente de luz vermelha. $\mathrm{O}$ tratamento químico envolveu $\mathrm{H} 2 \mathrm{O} 2(20 \%)$, $\mathrm{HF}(20 \%)$ e $\mathrm{HCl}(10 \%)$. Em seguida, as amostras foram peneiradas e os grãos de quartzo separadas na fração granulométrica na faixa 100-160 $\mu \mathrm{m}$. As amostras foram analisadas utilizando o Protocolo Single Aliquot Regenerative (SAR-dose), com pré-aquecimento de $160^{\circ} \mathrm{C}$ por 10 minutos e utilização de 5 alíquotas. As idades foram calculadas utilizando o Modelo de Idade Central (CAM).

A datação por LOE permite identificar o último evento de transporte sedimentar que expôs os grãos de quartzo ou feldspato à luz solar e, desse modo, o tempo decorrido desde a última deposição. O contato do quartzo com a radiação solar promove o esvaziamento do sinal de luminescência adquirido anteriormente. Ao final do transporte, a partir do momento em que o material é depositado ao abrigo da luz, inicia-se uma nova acumulação do sinal de luminescência (SALLUN et al., 2007; CORRÊA; SILVA; MELLO, 2008). Contudo, há situações em que o esvaziamento é incompleto, podendo levar a obtenção de idades superestimadas. 


\section{Resultados}

\subsection{Níveis e sequências deposicionais fluviais}

Na SEM, destacam-se as Superfícies Elevadas (SE), que correspondem às partes mais elevadas da região, sustentadas pelos quartzitos do Supergrupo Espinhaço. No interior da Serra, as áreas deprimidas, que correspondem aos terrenos de médios e baixos cursos dos principais cursos d'água (Chiqueiro, Datas, Congonhas, Sepultura e Paraúna) formam a Depressão de Gouveia (DG).

O canal do rio Paraúna e grande parte dos canais de seus afluentes (Areia, Chiqueiro, Datas, Palmital, Sepultura, Contagem e Rio Grande) possuem padrões majoritariamente sinuosos. Entretanto, mesmo em trechos de menor declividade, os segmentos de alto curso são predominantemente retilíneos, o que pode estar associado às rochas do Supergrupo Espinhaço, especialmente os quartzitos.

Nos segmentos de baixo curso, próximos às confluências com o Paraúna, e, sobretudo, em áreas onde predominam os granitos e gnaisses do Complexo Gouveia, os canais frequentemente apresentam maior sinuosidade. As condições de menor energia observadas nesses segmentos, associadas às menores declividades, $\mathrm{e}$ a influência das rochas granito-gnáissicas favorecem o aumento da sinuosidade. Apenas o Congonhas possui um segmento com padrão fluvial tipicamente meandrante. Ele possui um vale aberto que se estende desde o alto curso até a confluência com o rio Paraúna. Ao longo de seu vale é possível identificar feições deprimidas localizadas nas superfícies que margeiam o canal principal, típicas de meandros abandonados.

Os vales fluviais investigados podem ser divididos em dois grupos quanto aos níveis deposicionais em contexto de fundo de vale: um grupo com PI e N1 e outro com PI, N1 e N2. Não se observa nenhum padrão quanto ao número de níveis em contexto de vertente. Nos vales do Paraúna, Palmital, Areia, Datas (alto curso), Congonhas, Contagem e Tigre foram identificados dois níveis deposicionais (PI e N1). Nos vales do Chiqueiro, Datas (baixo curso), Rio Grande e Sepultura foram identificados três níveis (PI, N1 e N2). Nos fundos de vale, predominam depósitos mais recentes embutidos, embora também sejam identificados alguns níveis suavemente encaixados.

Os vales do Contagem e o baixo curso do Datas não possuem níveis em contexto de vertente. Nos demais, o número varia entre um e três. Nos vales do Palmital, alto curso Datas e do Sepultura há um nível (N2 - Palmital e Datas; e N3 - Sepultura). No Congonhas e Areia ocorrem dois níveis em cada vale (N2 e N3). No Chiqueiro (N3, N4 e N5), no Tigre (N2, N3 e N4) e no Rio Grande (N3, N4 e N5) há três níveis em contexto de vertente que estão sempre escalonados em relação aos mais antigos.

Os terraços localizados em fundos de vale possuem indícios da atuação de processos erosivos condicionados pela dinâmica fluvial atual, apresentando sinais de que estejam sendo erodidos e seus sedimentos remobilizados. Os terraços em contexto de vertente parecem mais resistentes aos processos erosivos atuais devido à sua composição granulométrica e mineralógica, predominantemente seixos de quartzo.

No vale do rio Paraúna foram identificados seis níveis deposicionais - PI, N1, N2, N3, N4 e N5 - cujas sequências deposicionais estão apresentadas no Quadro 2. A PI e o N1 são níveis pareados, bem preservados e em contexto de fundos de vale. Os níveis N2, N3, N4 e N5 se encontram em contexto de vertente, sendo que o N2 é pareado e os demais foram identificados apenas na margem direita. A PI se encontra embutida no N1 e os demais níveis estão escalonados. A distribuição transversal dos níveis deposicionais está representada na Figura 3. No médio e baixo curso são encontradas cascalheiras quartzosas, provavelmente associadas à mineração.

Quadro 2: Síntese das caraterísticas das sequências deposicionais fluviais do rio Paraúna - perfis descritos da base para o topo.

\begin{tabular}{|c|l|}
\hline Nível & \multicolumn{1}{|c|}{ Rio Paraúna } \\
\hline PI & $\begin{array}{l}\text { Fácies arenosa com grânulos de quartzo arredondados esparsos na matriz arenosa, com até } 2 \mathrm{~cm} \text { de diâmetro. Há presença de } \\
\text { estruturas plano-paralelas. }\end{array}$ \\
\hline N1 & $\begin{array}{l}\text { Duas fácies em transição abrupta: (i) fácies basal com cerca de } 40 \mathrm{~cm} \text { de espessura, composta por seixos autossuportados, em } \\
\text { matriz de areia grossa; (ii) fácies superior arenosa (areia fina a média), com cerca de 3,10 m de espessura. Não foram identificadas } \\
\text { estruturas sedimentares. }\end{array}$ \\
\hline N2 & $\begin{array}{l}\text { Fácies com } 80 \mathrm{~cm} \text { de espessura, seixos de quartzo com diâmetro entre 1 e } 10 \mathrm{~cm} \text {, sobre elúvio. Os seixos são arredondados e } \\
\text { subarredondados. }\end{array}$ \\
\hline
\end{tabular}




\begin{tabular}{|c|l|}
\hline N3 & $\begin{array}{l}\text { Duas fácies em transição abrupta: (i) fácies basal com } 60 \mathrm{~cm} \text { de espessura e predomínio de seixos de quartzo autossuportados, } \\
\text { mal selecionados (1 cm a } 20 \mathrm{~cm} \text { de diâmetro), subarredondados e arredondados; (ii) fácies com } 20 \mathrm{~cm} \text { de espessura, composta } \\
\text { por material arenoso (areia fina a média), de aspecto homogêneo e maciço. }\end{array}$ \\
\hline N4 & Fácies de seixos de quartzo autossuportados, arredondados, mal selecionados $(1 \mathrm{a} 20 \mathrm{~cm})$, bastante friáveis, sobre elúvio \\
\hline N5 & $\begin{array}{l}\text { Fácies arenosa (areia média a grossa) com } 2 \text { m de espessura e estratificação plano-paralela, sobre elúvio; seixos esparsos na } \\
\text { matriz, predominantemente de quartzo, subangulosos e subarredondados, com até } 10 \mathrm{~cm} \text { de diâmetro. }\end{array}$ \\
\hline
\end{tabular}
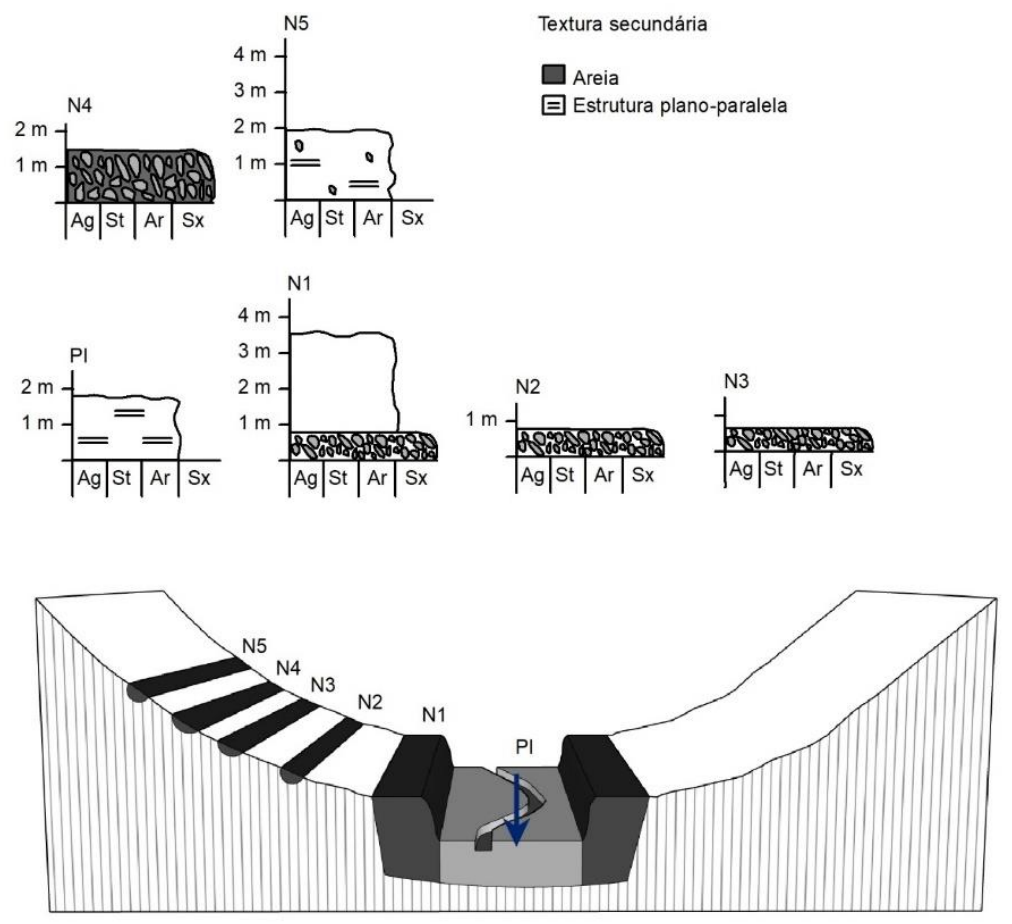

Figura 3. Organização transversal do vale fluvial do rio Paraúna e representação dos perfis estratigráficos síntese.

Foram encontrados quatro níveis deposicionais no vale do Congonhas - PI, N1, N2 e N3- e três no alto curso do Palmital - PI, N1 e N2 (Quadro 3). No Congonhas, a PI e o N1 estão em contexto de fundo de vale. A PI é pareada e o N1 isolado, identificado apenas na margem esquerda. Os níveis N2 e N3 possuem registros ao longo de todo o vale, estando em contexto de vertente e isolados, identificados apenas na margem direita. A PI se encontra embutida no N1, enquanto o N2 se encontra escalonado em relação ao N3. O leito é do tipo aluvial, predominando sedimentos arenosos. O fundo do vale é bastante amplo e está associado a um terreno com granitoides, sendo possível observar, em diversos pontos, as escarpas sustentadas pelos quartzitos. No vale do Palmital a PI e o N1 são mais preservados, sendo pareados e ocorrendo em contexto de fundo de vale. Já o N2 é o único nível em contexto de vertente, identificado apenas na margem direita. A PI se encontra embutida no N1, o qual é escalonado em relação ao N2. No baixo curso, o curso d'água aprofundou seu leito e o vale é mais encaixado. No alto curso, o leito fluvial é predominantemente aluvial, com barras arenosas expressivas. A distribuição transversal dos níveis deposicionais está representada na Figura 4.

Quadro 3: Síntese das caraterísticas das sequências deposicionais fluviais dos ribeirões Congonhas e Palmital perfis descritos da base para o topo.

\begin{tabular}{|c|l|}
\hline Nível & \multicolumn{1}{|c|}{ Ribeirão Congonhas } \\
\hline PI & $\begin{array}{l}\text { Fácies com base sob a lâmina d'água, areno-argilosa (areia fina), com cerca de } 2 \mathrm{~m} \text { de espessura, coloração escura associada à } \\
\text { presença de matéria orgânica. }\end{array}$ \\
\hline N1 & $\begin{array}{l}\text { Duas fácies em transição abrupta: (i) fácies basal com cerca de } 1,5 \mathrm{~m} \text { de espessura, composta predominantemente por seixos de } \\
\text { quartzo arredondados, mal selecionados e autossuportados, com até } 10 \mathrm{~cm} \text { de diâmetro, sobre elúvio; (ii) fácies superior com } 20 \\
\text { cm de espessura, composta por material arenoso (areia fina). Não foram identificadas estruturas sedimentares. }\end{array}$ \\
\hline
\end{tabular}




\begin{tabular}{|c|l|}
\hline N2 & $\begin{array}{l}\text { (i) fácies basal com } 1 \mathrm{~m} \text { de espessura, sobre elúvio, composta predominantemente por seixos de quartzo autossuportados, mal } \\
\text { selecionados, subarredondados a arredondados, cujo diâmetro varia entre } 1 \text { e } 5 \mathrm{~cm} \text {; (ii) fácies com cerca de } 1 \mathrm{~m} \text { de espessura, } \\
\text { arenosa (areia fina a média), de aspecto homogêneo e maciço. }\end{array}$ \\
\hline N3 & Fácies de seixos de quartzo autossuportados, mal selecionados, cujo diâmetro varia entre 1 e $10 \mathrm{~cm}$, sobre elúvio. \\
\hline PI & $\begin{array}{l}\text { Ribeirão Palmital } \\
\text { lâmina d'água; (ii) fácies superior composta de areia fina, com } 50 \text { cm de espessura, estruturas plano-paralelas, coloração } \\
\text { predominantemente clara com a parte superficial escurecida devido à matéria orgânica associada à vegetação atual. }\end{array}$ \\
\hline N1 & $\begin{array}{l}\text { (i) fácies basal argilosa com 1,5 m de espessura, aspecto homogêneo e maciço e cor escura devido à presença de matéria orgânica; } \\
\text { a base se encontra coberta pela lâmina d'água; (ii) fácies com 1,30 m de espessura, de material argiloso, com mosqueamentos } \\
\text { amarelados e escuros; (iii) fácies superior com } 70 \text { cm de espessura, areno-argilosa (areia fina) e de coloração escura. }\end{array}$ \\
\hline N2 & $\begin{array}{l}\text { Fácies com cerca de } 1 \text { m composta por areia média a grossa, com a presença de muitos seixos de quartzo subangulosos e } \\
\text { subarredondados, mal selecionados, cujo tamanho chega a } 5 \mathrm{~cm} \text {. É possível identificar a presença de estruturas plano-paralelas. }\end{array}$ \\
\hline
\end{tabular}
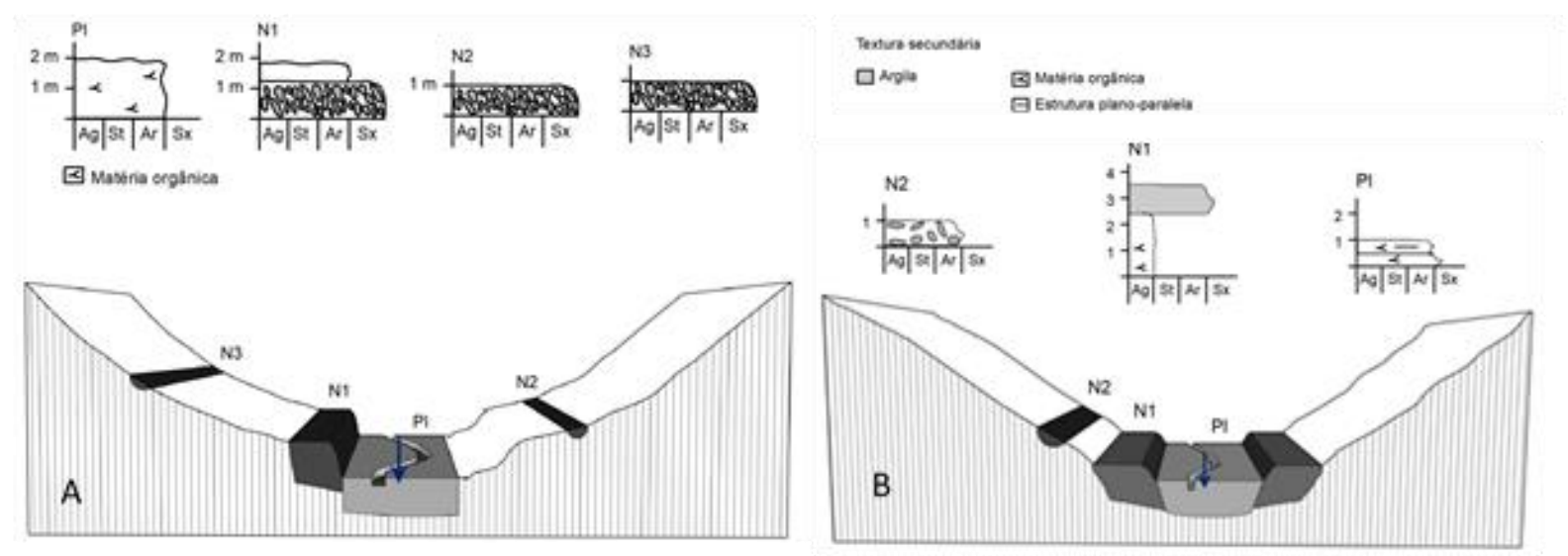

Figura 4: Organização transversal do vale fluvial dos ribeirões Congonhas (A) e Palmital (B) e representação dos perfis estratigráficos síntese.

Foram identificados quatro níveis deposicionais no vale do Sepultura - PI, N1, N2 e N3 - e dois no vale do Contagem - PI e N1 (Quadro 4). No Sepultura, a PI, o N1 e o N2 são níveis pareados e em contexto de fundo de vale. A PI se encontra embutida no N1 e este encaixado em relação ao N2. O N2 se encontra escalonado em relação ao N3, o único nível em contexto de vertente nesse vale. Predominam trechos com leito aluvial, com pequenos trechos de leito rochoso. No Contagem, os dois níveis são pareados e estão em contexto de fundo de vale. A PI está embutida no $\mathrm{N} 1$ e seus sedimentos parecem ser facilmente remobilizados durantes os períodos chuvosos. O leito fluvial é predominantemente aluvial, composto de material arenoso, mas com grande quantidade de seixos e blocos. Em alguns segmentos o leito é do tipo rochoso. A distribuição transversal dos níveis deposicionais está representada na Figura 5.

Quadro 4: Síntese das caraterísticas das sequências deposicionais fluviais dos córregos da Sepultura e da Contagem - perfis descritos da base para o topo.

\begin{tabular}{|c|l|}
\hline Nível & \multicolumn{1}{|c|}{ Córrego da Sepultura } \\
\hline PI & $\begin{array}{l}\text { Fácies com cerca de } 1 \mathrm{~m} \text { de espessura e base coberta pela lâmina d'água; material arenoso (areia média a grossa) com estruturas } \\
\text { plano-paralelas. }\end{array}$ \\
\hline N1 & $\begin{array}{l}\text { Fácies com cerca de } 3 \mathrm{~m} \text { de espessura e base coberta pela lâmina d'água; material arenoso (areia média a grossa) com } \\
\text { estratificação plano-paralela. }\end{array}$ \\
\hline
\end{tabular}




\begin{tabular}{|c|l|}
\hline N2 & $\begin{array}{l}\text { (i) fácies basal com cerca de } 40 \mathrm{~cm} \text { de espessura depositada sobre elúvio; seixos subarredondados e arredondados, } \\
\text { predominantemente de quartzo, entre } 5 \mathrm{a} 15 \mathrm{~cm} \text { de diâmetro, matacões de até } 30 \mathrm{~cm} \text { na base até grânulos na parte superior } \\
\text { (granodecrescência ascendente), suportados por matriz arenosa (areia média a grossa); (ii) fácies argilo-arenosa, aspecto maciço, } \\
\text { cerca de } 60 \mathrm{~cm} \text { de espessura; (iii) fácies argilosa, aspecto maciço, cerca de } 30 \mathrm{~cm} \text { de espessura; (iv) fácies superior argilo-arenosa, } \\
\text { coloração escura associada à matéria orgânica, cerca de } 70 \mathrm{~cm} \text { de espessura. }\end{array}$ \\
\hline PI & $\begin{array}{l}\text { Córrego da Contagem } \\
\text { (ii) fácies com } 20 \mathrm{~cm} \text { de espessura, arenosa (areia fina), de coloração clara, com estruturas plano-paralelas; (iii) fácies superior } \\
\text { areno-argilosa (areia fina) com cerca de } 20 \mathrm{~cm} \text { de espessura, coloração escura associada à matéria orgânica. }\end{array}$ \\
\hline N1 & $\begin{array}{l}\text { Fácies areno-argilosa (areia fina), com cerca de } 3,5 \mathrm{~cm} \text { de espessura, de coloração escura que varia ao longo do perfil e está } \\
\text { associada à presença de matéria orgânica. }\end{array}$ \\
\hline
\end{tabular}

A

A

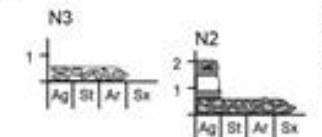

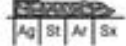

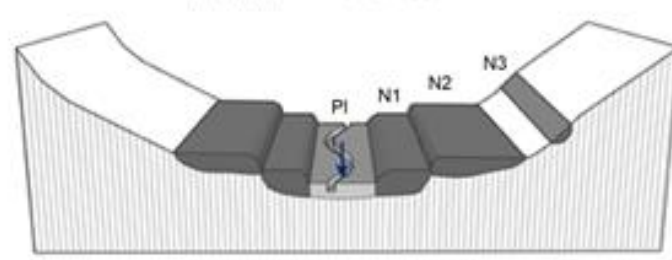

Theres sectudatis

口apbs

a Neis

\section{Ni}

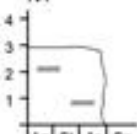

PI

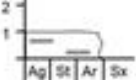

B

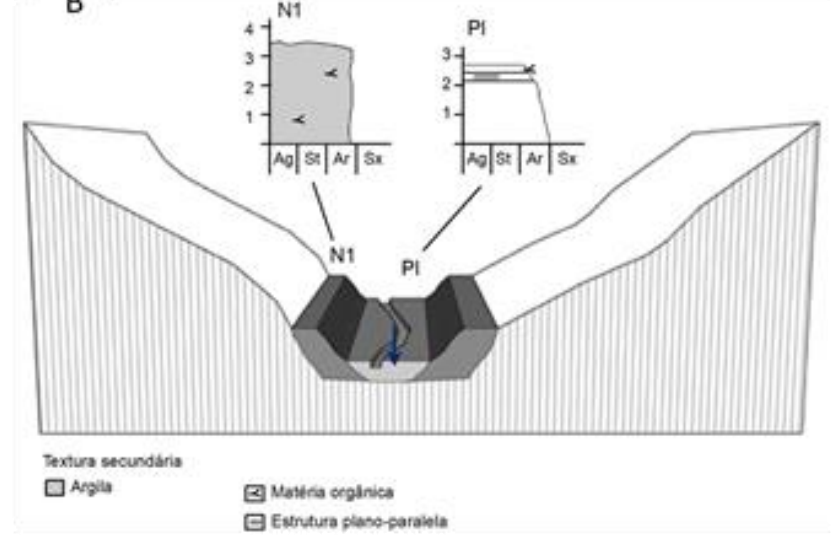

Figura 5: Organização transversal do vale fluvial do Córrego da Sepultura (A) e do Córrego da Contagem (B) e representação dos perfis estratigráficos síntese.

Nos vales do Chiqueiro e Rio Grande foram identificados seis níveis - PI, N1, N2, N3, N4 e N5 (Quadro 5). Nos dois vales, os níveis PI e N1, N2 e N3 estão em contexto de fundos de vale. No Chiqueiro a PI está embutida no N1 e este no N2. Os níveis N2, N3 e N4 se encontram escalonados em relação aos níveis imediatamente mais antigos. O N4 e o N5 foram identificados apenas na margem direita. Em alguns trechos o leito é rochoso, às vezes associado aos afloramentos de rochas básicas. No Rio Grande, a PI é embutida no N1, o qual é levemente encaixado em relação ao N2, e este é escalonado em relação ao N3. Todos os outros níveis são escalonados em relação aos níveis imediatamente mais antigos. Os níveis N3, N4 e N5 foram identificados apenas na margem direita. O leito fluvial é predominantemente aluvial, com trechos em que se destacam sedimentos arenosos e outros com presença significativa de seixos, matacões e até blocos. A distribuição transversal dos níveis deposicionais está representado na Figura 6.

Quadro 5: Síntese das caraterísticas das sequências deposicionais fluviais do ribeirão do Chiqueiro e do córrego Rio Grande - perfis descritos da base para o topo.

\begin{tabular}{|c|l|}
\hline Nível & \multicolumn{1}{|c|}{ Ribeirão do Chiqueiro } \\
\hline PI & Fácies arenosa (areia fina a média) com 2 m de espessura e presença de estruturas plano-paralelas. \\
\hline N1 & $\begin{array}{l}\text { Duas fácies em transição abrupta: (i) fácies com cerca de } 70 \mathrm{~cm} \text { de espessura, composta por seixos de quartzo subarredondados } \\
\text { e arredondados, com até } 15 \mathrm{~cm} \text { de diâmetro, e suportados por matriz arenosa (areia fina); (ii) fácies superior com cerca de 1,30 } \\
\text { m de espessura, arenosa (areia fina), com aspecto maciço. }\end{array}$ \\
\hline N2 & $\begin{array}{l}\text { (i) fácies basal sobre elúvio, com cerca de } 50 \mathrm{~cm} \text { de espessura, composta por seixos de quartzo autossuportados, subarredondados } \\
\text { e arredondados, mal selecionados, cujo tamanho varia entre } 5 \text { e } 10 \mathrm{~cm} \text {; (ii) fácies arenosa (areia fina) com } 3 \mathrm{~m} \text { de espessura e } \\
\text { aspecto maciço. }\end{array}$ \\
\hline
\end{tabular}




\begin{tabular}{|c|c|}
\hline N3 & $\begin{array}{l}\text { cies com cerca de } 1,80 \mathrm{~m} \text { de espessura, sobre elúvio; seixos de quartzo suportados por matriz arenosa (areia fina), } \\
\text { barredondados e arredondados, mal selecionados, com predomínio de seixos com até } 3 \mathrm{~cm} \text { (alguns matacões chegam a } 20 \mathrm{~cm} \\
\text { diâmetro). }\end{array}$ \\
\hline $\mathrm{N} 4$ & $\begin{array}{l}\text { cies com cerca de } 60 \mathrm{~cm} \text { de espessura, sobre elúvio; seixos de quartzo autossuportados, subarredondados e arredondados, mal } \\
\text { lecionados ( } 1 \text { a } 5 \mathrm{~cm} \text {, alguns seixos chegam a } 15 \mathrm{~cm} \text { ). }\end{array}$ \\
\hline \multirow[t]{2}{*}{ N5 } & $\begin{array}{l}\text { (i) fácies basal com cerca de } 60 \mathrm{~cm} \text { de espessura; material arenoso (areia média a grossa) com presença de grânulos e seixos } \\
\text { esparsos, sobre elúvio; (ii) fácies com cerca de } 40 \mathrm{~cm} \text { de espessura, composta por seixos mal selecionados, autossuportados, } \\
\text { arredondados, predominando quartzo, com diâmetro entre } 5 \text { e } 12 \mathrm{~cm} \text {. }\end{array}$ \\
\hline & \\
\hline PI & $\begin{array}{l}\text { Fácies arenosa (areia média a grossa), com } 50 \mathrm{~cm} \text { de espessura, com presença de seixos e matacões de tamanhos variados e } \\
\text { esparsos. }\end{array}$ \\
\hline N1 & $\begin{array}{l}\text { (i) fácies com cerca de } 50 \mathrm{~cm} \text { de espessura, predominando seixos de quartzo autossuportados, mal selecionados que chegam a } \\
30 \mathrm{~cm} \text { de diâmetro, arredondados; (ii) fácies com } 30 \mathrm{~cm} \text { de areia grossa com estratificação plano-paralela; (iii) fácies com } 30 \mathrm{~cm} \\
\text { de espessura, composta por material arenoso (areia média a grossa) com seixos de quartzo esparsos, com diâmetro de até } 5 \mathrm{~cm} \text {. }\end{array}$ \\
\hline N2 & $\begin{array}{l}\text { (i) fácies basal de seixos (até } 15 \mathrm{~cm} \text { de diâmetro) e matacões autossuportados com cerca de } 50 \mathrm{~cm} \text { de espessura e depositada sobre } \\
\text { elúvio; predominam clastos de quartzo, subarredondados e arredondados; (ii) material argilo-arenoso (areia fina) com 1,80 m de } \\
\text { espessura, com estruturas plano-paralelas; (iii) areia fina com estruturas plano-paralelas e } 50 \mathrm{~cm} \text { de espessura; (iv) material } \\
\text { areno-argiloso (areia fina) com } 40 \mathrm{~cm} \text { de espessura e indícios de pedogênese. O pacote está bastante bioturbado, principalmente } \\
\text { pela ação de cupins e formigas. }\end{array}$ \\
\hline N3 & $\begin{array}{l}\text { Fácies depositada sobre elúvio, com } 30 \mathrm{~cm} \text { de espessura, composta por seixos de quartzo autossuportados, mal selecionados, } \\
\text { chegando a } 7 \mathrm{~cm} \text { de diâmetro. }\end{array}$ \\
\hline N4 & $\begin{array}{l}\text { Fácies depositada sobre elúvio, com } 80 \mathrm{~cm} \text { de espessura, composta por seixos de quartzo autossuportados, mal selecionados, } \\
\text { predominando seixos com até } 5 \mathrm{~cm} \text {, sendo possível observar alguns seixos esparsos com até } 10 \mathrm{~cm} \text { de diâmetro. }\end{array}$ \\
\hline N5 & $\begin{array}{l}\text { Fácies sobre elúvio com } 1,50 \mathrm{~m} \text { de espessura, composta de seixos e matacões autossuportados, predominantemente de quartzo, } \\
\text { mas também de quartzito e outras litologias; os clastos chegam a } 30 \mathrm{~cm} \text { de diâmetro. }\end{array}$ \\
\hline
\end{tabular}

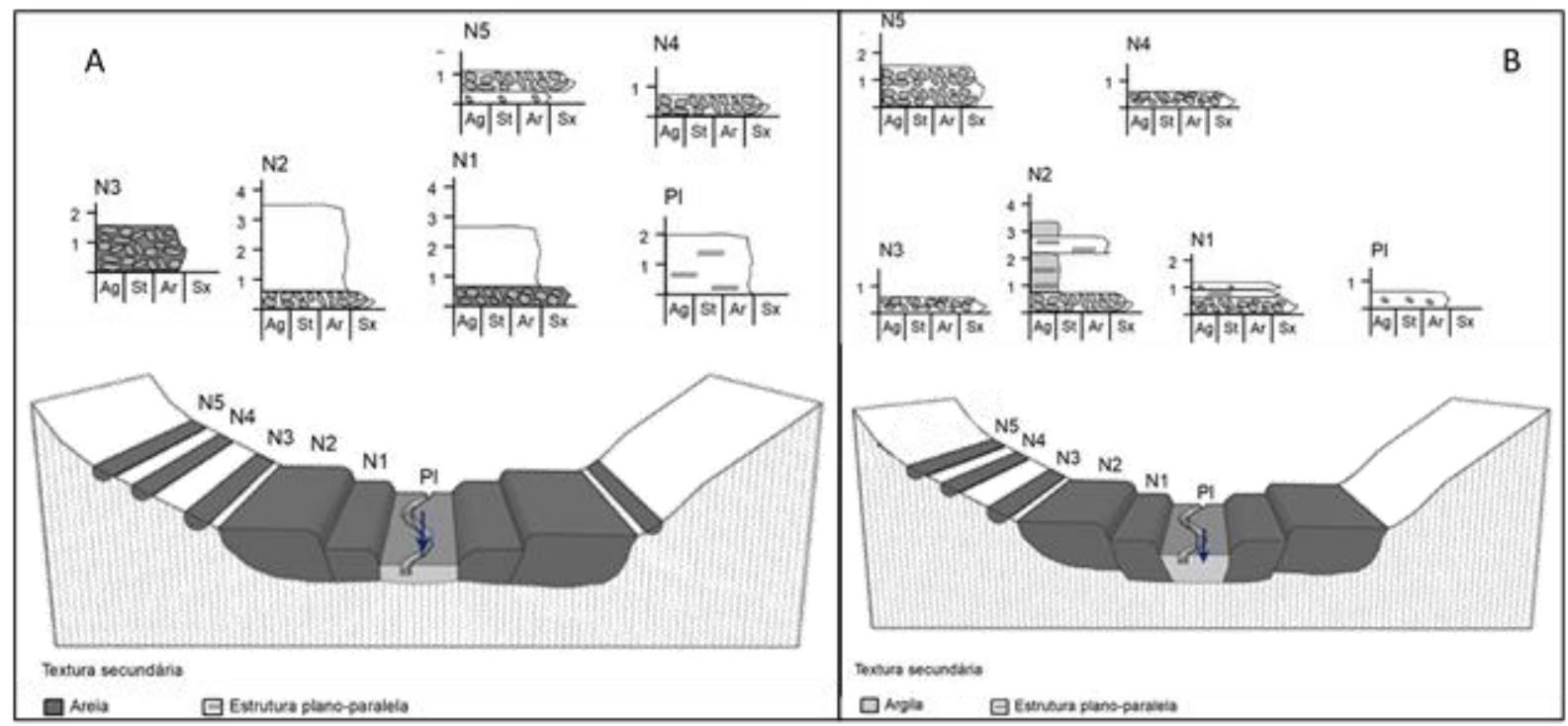

Figura 6: Organização transversal do vale fluvial do ribeirão do Chiqueiro (A) e do córrego Rio Grande (B) e representação dos perfis estratigráficos síntese.

Juntamente com o Rio Grande, os cursos d'água Datas, Areia e Tigre são afluentes do Chiqueiro e drenam a DG. Foram identificados quatro níveis deposicionais no vale do Areia (PI, N1, N2 e N3), três no vale do Datas (PI, 
N1 e N2) e cinco no vale do Tigre (PI, N1, N2, N3 e N4), conforme mostra o Quadro 6. No Areia, a PI e o N1 são níveis pareados e se encontram em contexto de fundo de vale, enquanto o N2 e o N3 foram identificados apenas na margem direita e estão em contexto de vertente. A PI está encaixada em relação ao N1, enquanto este e o N2 estão escalonados em relação aos níveis imediatamente mais antigos. Predominam trechos de leito aluvial, com material arenoso. No Datas, dois knickpoints permitiram individualizar dois segmentos com dinâmicas fluviais distintas. O alto curso corresponde à uma área elevada, sustentada pelas litologias mais resistentes da Formação Sopa-Brumadinho, enquanto o baixo curso corresponde a parte da DG. No alto curso, a PI e o N1 são níveis pareados, em fundo de vale, estando a PI encaixada em relação ao N1. O N1 está escalonado em relação ao N2 e este foi identificado apenas na margem direita. No baixo curso, os três níveis estão em contexto de fundo de vale e são pareados. A PI está embutida no N1 e este encaixado em relação ao N2. No Tigre, a PI e o N1 são níveis pareados e em contexto de fundo de vale. Os níveis N2, N3 e N4 são isolados, sendo o N2 e o N3 identificados na margem direita e o N4 na margem esquerda. A PI está embutida no N1. Os níveis N1, N2 e N3 estão escalonados em relação aos níveis imediatamente mais antigos. O leito fluvial é predominantemente aluvial (material arenoso), havendo trechos com seixos e matacões e trechos de leito rochoso. A distribuição transversal dos níveis deposicionais está representa na Figura 7.

Quadro 6: Síntese das caraterísticas das sequências deposicionais fluviais dos ribeirões do da Areia e Datas e do Córrego do Tigre - perfis descritos da base para o topo.

\begin{tabular}{|c|c|}
\hline Nível & Ribeirão da Areia \\
\hline PI & $\begin{array}{l}\text { Fácies com a base coberta pela lâmina d'água, com cerca de } 3 \mathrm{~m} \text { de espessura, composta por material arenoso (areia média a } \\
\text { grossa). }\end{array}$ \\
\hline N1 & $\begin{array}{l}\text { (i) fácies basal depositada sobre elúvio, com cerca de } 2 \mathrm{~m} \text { de espessura, composta predominantemente por seixos e matacões de } \\
\text { quartzo autossuportados, mal selecionados ( } 2 \text { a } 30 \mathrm{~cm} \text { de diâmetro), predominando seixos pequenos, subarredondados e } \\
\text { arredondados; (ii) fácies areno-argilosa (areia fina a média) com cerca de } 2 \mathrm{~m} \text { de espessura, coloração avermelhada, aspecto maciço; } \\
\text { (iii) fácies com } 1 \mathrm{~m} \text { de espessura, composta por seixos e matacões esparsos, com até } 20 \mathrm{~cm} \text { de diâmetro, suportados por matriz } \\
\text { areno-argilosa (areia fina) de coloração avermelhada. }\end{array}$ \\
\hline N2 & $\begin{array}{l}\text { Fácies com 1,50 m de espessura depositada sobre elúvio composta predominantemente por seixos de quartzo autossuportados, } \\
\text { mal selecionados ( } 1 \text { a } 15 \mathrm{~cm} \text { de diâmetro), arredondados e subarredondados. }\end{array}$ \\
\hline \multirow[t]{2}{*}{ N3 } & $\begin{array}{l}\text { Fácies com } 30 \mathrm{~cm} \text { de espessura depositada sobre elúvio e composta de seixos de quartzo autossuportados, mal selecionados (1 a } 5 \\
\mathrm{~cm} \text { de diâmetro), subangulosos e subarredondados. }\end{array}$ \\
\hline & Ribeirão Datas \\
\hline PI & $\begin{array}{l}\text { Alto curso: (i) fácies com } 20 \mathrm{~cm} \text { de espessura, arenosa (areia fina), coloração escura associada à matéria orgânica, estruturas plano- } \\
\text { paralelas; (ii) fácies com } 30 \mathrm{~cm} \text { de espessura, arenosa (areia média a grossa), com seixos esparsos e estruturas plano-paralelas; (iii) } \\
\text { fácies com } 50 \mathrm{~cm} \text { de espessura, arenosa (areia fina a média), estruturas plano-paralelas e fragmentos de matéria orgânica; (iv) fácies } \\
\text { arenosa (areia média a grossa) com } 25 \mathrm{~cm} \text { de espessura, maciça, com grânulos de quartzo e matéria orgânica. } \\
\text { Baixo curso: fácies basal sob a lâmina d'água, com cerca de } 1 \mathrm{~m} \text { de espessura, composta por material areno-argiloso com estruturas } \\
\text { plano-paralelas. }\end{array}$ \\
\hline N1 & $\begin{array}{l}\text { Alto curso: (i) Material arenoso concrecionado por ferro e coloração avermelhada, depositado sobre elúvio com cerca de } 10 \mathrm{~cm} \text { de } \\
\text { espessura; (ii) Material arenoso (areia média a grossa), com } 50 \mathrm{~cm} \text { de espessura e coloração escura associada à matéria orgânica; } \\
\text { (iii) fácies com } 35 \mathrm{~cm} \text { de espessura, composta por seixos de quartzo subarredondados e arredondados, mal selecionados ( } 1 \text { a e } 15 \\
\text { cm de diâmetro), suportados por matriz arenosa (areia fina a média); (iv) material areno-argiloso (areia fina a média) maciço, com } \\
70 \mathrm{~cm} \text { de espessura; presença de seixos de quartzo esparsos, mal selecionados, angulosos a arredondados, com até } 8 \mathrm{~cm} \text { de } \\
\text { diâmetro. } \\
\text { Baixo curso: (i) Nível de seixos de quartzo com } 80 \mathrm{~cm} \text { de espessura; mal selecionados, suportados por matriz arenosa (areia média } \\
\text { a grossa), predominam clastos de até } 5 \mathrm{~cm} \text { de diâmetro; (ii) fácies arenosa (areia média a grossa) com } 60 \mathrm{~cm} \text { de espessura e }\end{array}$ \\
\hline
\end{tabular}




\begin{tabular}{|c|c|}
\hline & $\begin{array}{l}\text { estratificação cruzada; (iii) fácies arenosa (areia grossa) com } 50 \mathrm{~cm} \text { de espessura, maciça, com seixos de quartzo com até } 2 \mathrm{~cm} \text { de } \\
\text { diâmetro; (iv) fácies arenosa com } 10 \mathrm{~cm} \text { de espessura (areia fina), cor avermelhada e estruturas plano-paralelas. }\end{array}$ \\
\hline $\mathrm{N} 2$ & $\begin{array}{l}\text { Alto curso: (i) fácies basal arenosa (areia grossa) concrecionada por ferro, com } 10 \mathrm{~cm} \text { de espessura; (ii); fácies arenosa (areia grossa) } \\
\text { maciça com } 50 \mathrm{~cm} \text { de espessura; (iii) fácies arenosa (areia fina a média) maciça, com } 50 \mathrm{~cm} \text { de espessura, de coloração escura } \\
\text { associada à presença de matéria orgânica. } \\
\text { Baixo curso: (i) fácies depositada sobre elúvio, } 30 \mathrm{~cm} \text { de espessura, seixos de quartzo bem selecionados (clastos de } 3 \mathrm{~cm} \text { ), suportados } \\
\text { por matriz arenosa (areia fina); (ii) fácies areno-argilosa (areia fina a média), avermelhada, aspecto maciço; e (iii) fácies com } 20 \mathrm{~cm} \\
\text { de espessura, seixos de quartzo bem selecionados ( } 5 \mathrm{~cm} \text { de diâmetro) suportados por matriz arenosa (areia fina). }\end{array}$ \\
\hline \multirow[t]{2}{*}{$\mathrm{N}$} & $\begin{array}{l}\text { Pacote sedimentar de origem antrópica composto por uma sequência de camadas arenosas e argilosas, com presença de estruturas } \\
\text { plano-paralelas. }\end{array}$ \\
\hline & Córrego do Tigre \\
\hline PI & $\begin{array}{l}\text { (i) fácies (20 cm de espessura) de seixos de quartzo autossuportados, mal selecionados, com tamanho entre } 2 \text { e } 15 \mathrm{~cm} \text {, } \\
\text { subarredondados e arredondados; (ii) fácies arenosa (areia média a grossa) com cerca de } 1,30 \mathrm{~m} \text { de espessura e com grânulos de } \\
\text { quartzo esparsos. }\end{array}$ \\
\hline N1 & Nível no qual a PI está embutida e que recobre a sua base; cerca de 2 m de areia média a grossa. \\
\hline N2 & $\begin{array}{l}\text { Nível de seixos sobre elúvio com } 30 \mathrm{~cm} \text { de espessura; clastos de quartzo autossuportados mal selecionados ( } 2 \text { a } 15 \text { cm de diâmetro), } \\
\text { subarredondados a arredondados. }\end{array}$ \\
\hline N3 & $\begin{array}{l}\text { Nível de seixos sobre elúvio com cerca de } 60 \mathrm{~cm} \text { de espessura; clastos de quartzo autossuportados, com } 2 \text { a } 15 \mathrm{~cm} \text { de diâmetro, mal } \\
\text { selecionados, subarredondados a arredondados, com matacões esparsos. }\end{array}$ \\
\hline N4 & $\begin{array}{l}\text { (i) Nível de seixos com } 1,5 \mathrm{~m} \text { de espessura; clastos de quartzo de até } 20 \mathrm{~cm} \text { de diâmetro; (ii) fácies com cerca de } 30 \mathrm{~cm} \text { de espessura, } \\
\text { composta predominantemente por seixos de quartzo suportados por matriz argilo-arenosa, mal selecionados, geralmente com } \\
\text { menos de } 5 \mathrm{~cm} \text { de diâmetro, subangulosos a subarredondados. }\end{array}$ \\
\hline
\end{tabular}

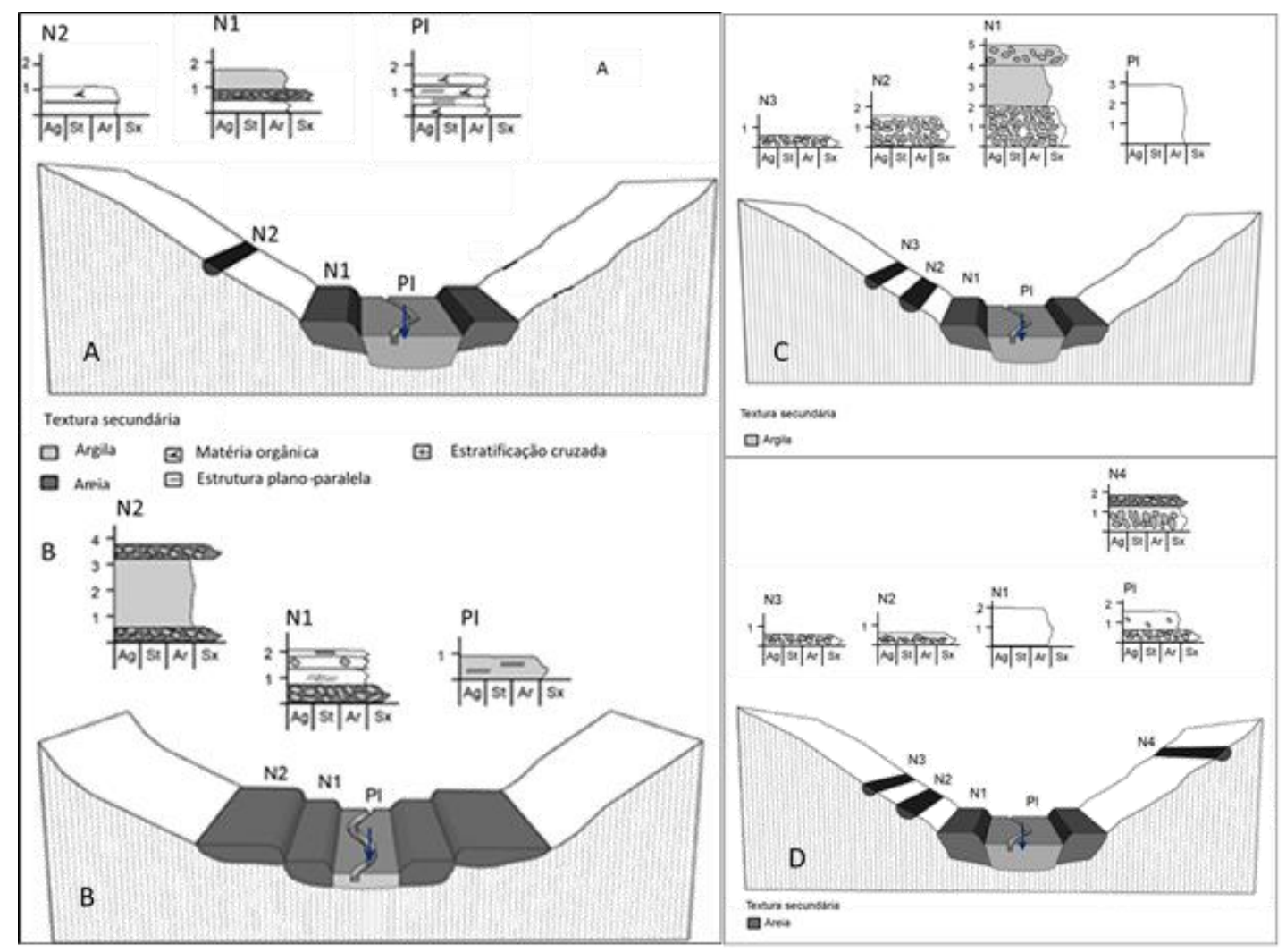

Figura 7: Organização transversal dos vales fluviais dos ribeirões Datas (alto curso - A; baixo curso B) e da Areia (C) e do Córrego do Tigre (D) e representação dos perfis estratigráficos síntese. 


\subsection{Idades obtidas por $L O E$}

Na Tabela 2 constam os resultados da datação de sedimentos por LOE (protocolo SAR, 5 alíquotas), totalizando 24 amostras. As idades variam de $170 \pm 25$ no vale do Congonhas a $26.350 \pm 4.470$ no vale do Sepultura

Tabela 2: Resultados da datação dos depósitos via LOE (SAR). Th - tório; U - urânio; K - potássio;

\begin{tabular}{|c|c|c|c|c|c|c|c|c|}
\hline \multirow[b]{2}{*}{ Curso } & \multirow{4}{*}{ Código } & \multirow{4}{*}{ Nível } & \multirow[b]{2}{*}{ Th } & \multirow[b]{2}{*}{$\mathbf{U}$} & \multirow[b]{2}{*}{$\mathbf{K}$} & \multicolumn{3}{|c|}{ Dose } \\
\hline & & & & & & Dose anual & & Idade \\
\hline \multirow[b]{2}{*}{ fluvial } & & & & & & & acumulada & \\
\hline & & & (ppm) & (ppm) & $\%$ & \multicolumn{3}{|c|}{ (Gy) } \\
\hline \multirow{5}{*}{ Paraúna } & D01 & PI & $4,254 \pm 0,153$ & $1,822 \pm 0,796$ & $0,682 \pm 0,099$ & $1.680 \pm 320$ & 0,3 & $180 \pm 40$ \\
\hline & D02 & PI & $2.600 \pm 0,311$ & $3,596 \pm 1,145$ & $0,931 \pm 0,135$ & $2.600 \pm 460$ & 0,7 & $270 \pm 60$ \\
\hline & & & & & & & & \\
\hline & D03 & N1 & $21,231 \pm 0,764$ & $8,943 \pm 0,122$ & $1,757 \pm 0,255$ & $5.800 \pm 350$ & 5,4 & $930 \pm 100$ \\
\hline & D04 & N3 & $31,879 \pm 1,148$ & $13,521 \pm 0,448$ & $2,195 \pm 0,318$ & $8.100 \pm 530$ & 34,1 & $4.200 \pm 480$ \\
\hline \multirow{5}{*}{ Congonhas } & D05 & PI & $14,609 \pm 0,526$ & $5,011 \pm 0,384$ & $1,040 \pm 0,151$ & $3.510 \pm 290$ & 0,6 & $170 \pm 25$ \\
\hline & D06 & PI & $2,769 \pm 0,100$ & $1,612 \pm 0,321$ & $0,760 \pm 0,110$ & $1.530 \pm 200$ & 0,9 & $590 \pm 110$ \\
\hline & & & & & & & & \\
\hline & D07 & N2 & $59,049 \pm 2,126$ & $13,996 \pm 0,645$ & $2,179 \pm 0,316$ & $10.270 \pm 650$ & 57,4 & $5.600 \pm 630$ \\
\hline & D08 & N2 & $30,852 \pm 1,111$ & $9,869 \pm 0,774$ & $2,627 \pm 0,381$ & $7.520 \pm 675$ & 43,5 & $5.790 \pm 810$ \\
\hline \multirow{2}{*}{ Palmital } & D09 & N1 & $2,592 \pm 0,093$ & $1,484 \pm 0,321$ & $0,535 \pm 0,078$ & $1.250 \pm 170$ & 2,9 & $2.320 \pm 430$ \\
\hline & D10 & N2 & $14,575 \pm 0,525$ & $4,416 \pm 0,425$ & $1,097 \pm 0,159$ & $3.500 \pm 310$ & 40,5 & $11.560 \pm 1.610$ \\
\hline Contagem & D11 & N1 & $5,143 \pm 0,185$ & $2,147 \pm 0,076$ & $0,862 \pm 0,125$ & $1.900 \pm 160$ & 31,8 & $16.750 \pm 2.260$ \\
\hline \multirow{3}{*}{ Sepultura } & D12 & N1 & $4,229 \pm 0,152$ & $1,968 \pm 0,715$ & $0,532 \pm 0,077$ & $1.515 \pm 275$ & 1,1 & $730 \pm 170$ \\
\hline & & & & & & & & \\
\hline & D13 & N2 & $3,028 \pm 0,109$ & $2,265 \pm 0,365$ & $0,675 \pm 0,098$ & $1.700 \pm 200$ & 44,6 & $26.350 \pm 4.470$ \\
\hline \multirow{3}{*}{ Chiqueiro } & D14 & N1 & $6,747 \pm 0,243$ & $2,808 \pm 0,505$ & $1,074 \pm 0,156$ & $2.500 \pm 310$ & 3,7 & $1.480 \pm 250$ \\
\hline & D15 & N2 & $13,326 \pm 0,480$ & $4,191 \pm 0,600$ & $1,835 \pm 0,266$ & $4.060 \pm 460$ & 12,2 & $3.000 \pm 490$ \\
\hline & D16 & N3 & $15,612 \pm 0,562$ & $5,805 \pm 0,624$ & $2,945 \pm 0,427$ & $5.710 \pm 640$ & 64,9 & $11.370 \pm 1.850$ \\
\hline \multirow{5}{*}{ Rio Grande } & D17 & PI & $19,316 \pm 0,695$ & $7,233 \pm 0,236$ & $2,173 \pm 0,315$ & $5.710 \pm 435$ & 3,6 & $630 \pm 80$ \\
\hline & D18 & N1 & $21,041 \pm 0,757$ & $8,176 \pm 0,271$ & $2,761 \pm 0,400$ & $6.650 \pm 540$ & 19,8 & $3.000 \pm 390$ \\
\hline & & & & & & & & \\
\hline & D19 & N1 & $26,915 \pm 0,969$ & $8,494 \pm 0,174$ & $1,192 \pm 0,173$ & $5.530 \pm 295$ & 15,2 & $2.750 \pm 285$ \\
\hline & D20 & N2 & $37,230 \pm 1,340$ & $13,965 \pm 0,255$ & $4,048 \pm 0,587$ & $10.390 \pm 770$ & 5,4 & $520 \pm 65$ \\
\hline \multirow{3}{*}{ Areia } & D21 & PI & $10,378 \pm 0,374$ & $3,707 \pm 0,279$ & $1,416 \pm 0,205$ & $3.330 \pm 310$ & 1,3 & $390 \pm 55$ \\
\hline & & & & & & & & \\
\hline & D22 & N2 & $18,711 \pm 0,674$ & $7,521 \pm 0,349$ & $1,538 \pm 0,223$ & $4.890 \pm 370$ & 46,8 & $9.575 \pm 1.200$ \\
\hline & D23 & PI & $1,212 \pm 0,044$ & $1,442 \pm 0,078$ & $0,554 \pm 0,080$ & $1.220 \pm 105$ & 1,1 & $900 \pm 120$ \\
\hline
\end{tabular}




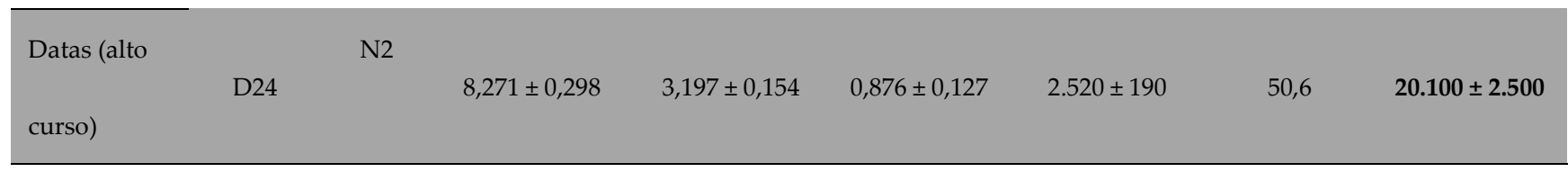

Na Tabela 3 constam informações que permitem avançar na análise da confiabilidade dos resultados obtidos com as amostras. Em 13 amostras os valores do teste de reciclagem estão fora dos padrões indicados pela literatura. Destacam-se as amostras D06, D19, D20 e D21, cujos valores de algumas alíquotas, mesmo considerando a margem de erro, são inferiores ao recomendado $(0,9)$. Os valores dos testes de reciclagem devem variar entre 0,9 e 1,1 para serem considerados confiáveis. Valores fora do intervalo mencionado sugerem que a amostra pode ser rejeitada (WINTLE; MURRAY, 2006).

Tabela 3: Intervalos dos valores referentes aos testes de reciclagem e de recuperação, o percentual de umidade e a distribuição conforme histograma de doses equivalentes.

\begin{tabular}{|c|c|c|c|c|}
\hline Amostra & Teste de reciclagem & Teste de recuperação (\%) & Umidade (\%) & Distribuição (gráfico) \\
\hline D01 & 0,94 a 1,05 & $-1,1$ a 7,2 & 1,1 & Unimodal \\
\hline D02 & 0,90 a 0,95 & $-2,4$ a 2,4 & 18,1 & Bimodal \\
\hline D03 & 0,83 a 0,94 & 0,2 a 0,4 & 5,6 & Bimodal \\
\hline D04 & 0,94 a 1,05 & $-0,3$ a 0,0 & 9,9 & Bimodal \\
\hline D05 & 0,98 a 1,17 & $-22,9$ a 16,0 & 15 & Unimodal \\
\hline D06 & 0,41 a 1,45 & $-65,5$ a 0,4 & 17,7 & Bimodal \\
\hline D07 & 0,91 a 0,96 & $-0,2$ a 0,1 & 7,7 & Bimodal \\
\hline D08 & 0,88 a 0,95 & $-0,1$ a 0,1 & 11,6 & Bimodal \\
\hline D09 & 0,89 a 0,93 & $-0,7$ a $-0,1$ & 21,1 & Unimodal \\
\hline D10 & 0,88 a 0,94 & $-0,1$ a 0,0 & 5,9 & Unimodal \\
\hline D11 & 0,86 a 0,92 & 0,1 a 0,2 & 22,4 & Bimodal \\
\hline D12 & 0,91 a 1,02 & $-1,9$ a 0,2 & 13,9 & Unimodal \\
\hline D13 & 0,91 a 0,96 & $-0,3$ a 0,0 & 1,6 & Unimodal \\
\hline D14 & 0,89 a 0,96 & $-1,5$ a $-0,2$ & 5,4 & Bimodal \\
\hline D15 & 0,84 a 0,87 & $-0,4$ a 0,0 & 9,0 & Bimodal \\
\hline D16 & 0,90 a 0,97 & $-0,5$ a 0,2 & 11,5 & Bimodal \\
\hline D17 & 0,86 a 1,00 & $-0,4$ a 0,1 & 2,1 & Bimodal \\
\hline D18 & 0,91 a 0,99 & $-0,2$ a 0,3 & 3,6 & Bimodal \\
\hline D19 & 0,78 a 1,26 & $-0,3$ a 0,4 & 7,0 & Unimodal \\
\hline D20 & 0,85 a 0,92 & $-0,4$ a 0,0 & 12,6 & Unimodal \\
\hline D21 & 0,75 a 0,92 & $-0,8$ a 1,6 & 6,1 & Unimodal \\
\hline D22 & 0,93 a 0,98 & 0,0 a 0,1 & 16,8 & Bimodal \\
\hline D23 & 0,92 a 1,09 & $-3,1$ a $-0,5$ & 1,9 & Unimodal \\
\hline D24 & 0,86 a 0,90 & $-0,1$ a 0,0 & 3,5 & Unimodal \\
\hline
\end{tabular}

No teste de recuperação, apenas a amostra D05 apresentou em alguma alíquota valor superior a $10 \%$. O teste de recuperação serve para avaliar se a alíquota se comporta como um dosímetro natural e para verificar se os parâmetros experimentais utilizados foram adequados. De modo geral, o valor encontrado para cada amostra no teste de recuperação não deve exceder 10 (GUEDES et al., 2013).

Nas datações por LOE, a incerteza no valor das idades depende das condições de reprodução dos cristais da amostra e é em torno de $10 \%$. A concentração de umidade interfere no percentual de incerteza, sendo que concentrações superiores a 15\% podem elevar a incerteza para 20\% (MAIA et al., 2011). As amostras D02, D06, D09, 
D11 e D22 apresentaram valores superiores ao recomendado pela literatura. Os valores elevados relativos à umidade revelam o cuidado com as interpretações que consideram as idades obtidas com essas amostras.

A distribuição modal nos gráficos é outro aspecto importante. Uma distribuição normal indica o esvaziamento completo do sinal de LOE antes do soterramento, enquanto uma distribuição bimodal provavelmente seja resultado do esvaziamento incompleto (GUEDES et al., 2013). A partir da observação dos gráficos de histograma de doses equivalentes, verifica-se que 13 amostras apresentam gráficos bimodais, indicando a possibilidade de esvaziamento parcial do sinal de luminescência.

Considerando esse conjunto de informações, é preciso considerar com cuidado as datações obtidas sobretudo os dados referentes às amostras do vale do Paraúna (D02, D03 e D04), do Congonhas (D06, D07 e D08), do Contagem (D11), do Chiqueiro (D14, D15, D16), do Rio Grande (D17, D18) e do Areia (D22).

\section{Discussão}

\subsection{Processos fluviais e configuração geomorfológica regional}

A incisão fluvial promovida pelo Rio Paraúna teve papel importante na evolução do nível de base regional da SEM, sobretudo para a DG. Ao promover o aprofundamento de seu leito, o Rio possibilitou a intensificação do rebaixamento do relevo e a individualização em dois compartimentos geomorfológicos. Assim, ao longo de parte do Pleistoceno Superior e do Holoceno, os processos fluviais se aproveitaram de uma janela estrutural, que facilitou a exposição de rochas mais tenras, e modelaram a DG no interior da Serra. Nos limites da bacia do rio Paraúna, as rochas mais resistentes do Supergrupo Espinhaço, sobretudo os quartzitos, condicionaram a manutenção das SE.

Os processos erosivos e a morfogênese têm sido condicionados de forma distinta por fatores endógenos e exógenos nos dois compartimentos geomorfológicos. Simultaneamente, os processos fluviais contribuem para a evolução desses compartimentos na SEM. A DG se expande, sobretudo, através das bacias do Chiqueiro e do Congonhas, além de parte do vale do Paraúna e do baixo curso do Sepultura. A DG configura uma importante superfície rebaixada no interior da Serra do Espinhaço, cujo nível de base regional se situa no trecho em que o Rio Paraúna sai da Serra, no contato entre o Supergrupo Espinhaço e o Grupo Macaúbas/Bambuí, a cerca de 900 m de altitude. Entre esse ponto até a base da escarpa oeste da Serra, na Depressão do São Francisco, situada a cerca de $550 \mathrm{~m}$ de altitude, há um desnível com cerca de $350 \mathrm{~m}$. Além dessas características geomorfológicas que conferem energia ao rio Paraúna em sua saída da Serra, deve-se considerar a influência da litoestrutura e da neotectônica sobre a intensidade dos processos geomorfológicos regionais e locais.

Apesar de os vales apresentarem diferentes números de níveis deposicionais, foi possível estabelecer correlações. Os vales podem ser diferenciados de acordo com a sua localização nas SE ou na DG. Na DG, há dois elementos que conferem certa homogeneidade: os blocos com mergulho e/ou basculados para leste, condicionando a migração dos canais para leste e a estabilização do nível de base regional representado pelo Rio Paraúna. O mergulho/basculamento dos blocos também dificulta a incisão fluvial do Rio Paraúna que flui na direção E-W. Quanto aos vales localizados nas SE, as rupturas de declive, observadas nos perfis longitudinais dos cursos d'água, podem ser decorrentes da diferença de resistência litológica entre os compartimentos. Essas rupturas representam as anomalias que podem ser identificadas a partir da análise morfométrica.

As evidências morfológicas e algumas características dos níveis deposicionais corroboram com a hipótese de ocorrência de movimentações neotectônicas na evolução geomorfológica regional. No entanto, não foram identificadas evidências diretas em campo em termos da cinemática da movimentação, como terraços ou outras coberturas superficiais deslocadas por falhas.

Os fundos de vale investigados têm papel importante para compreender a evolução geomorfológica mais recente, sobretudo ao longo do Holoceno. A dinâmica hidrossedimentar moderna possui registros importantes nesses fundos de vale e sua interpretação permite estabelecer relações com o quadro litoestrutural regional, bem como com as condições mais recentes dos níveis de base.

Com o devido cuidado, conforme dados da LOE, as PI apresentam idades inferiores a $900 \pm 120$ anos. No Paraúna e no Congonhas, esses níveis são bastante recentes, $180 \pm 40$ anos e $170 \pm 25$ anos, respectivamente, provavelmente associado às alterações na dinâmica hidrossedimentar desses canais, em resposta à intensificação das atividades antrópicas. Outras PI são mais antigas e refletem uma tendência de alteração na dinâmica hidrossedimentar que remonta há, no máximo, $900 \pm 120$ anos. 
Como algumas idades obtidas remetem a um período de formação anterior à intensificação das atividades antrópicas, supõe-se que a dinâmica hidrossedimentar apresentou sinais de alterações ao longo do Holoceno. Entretanto, a retirada da vegetação e a instalação de atividades humanas como agricultura, pecuária e mineração, devem ter intensificado as taxas de erosão nas encostas e fundos de vales, aumentado a carga sedimentar e condicionado os processos fluviais e os ambientes deposicionais. A mineração, praticada nas margens fluviais e em níveis deposicionais, provavelmente revolveu grande quantidade de material, que foi transportado com maior facilidade para os cursos d'água.

Ao observar as idades de níveis N1 e N2 (D03, D07, D08, D10, D11, D12, D13, D14, D15, D18, D19, D20, D22 e D24 - Tabela 2) e as suas características faciológicas, pode-se considerar que o contexto ambiental pretérito apresentava sinais de entulhamento dos canais devido à estabilização do nível de base regional. A partir desses níveis em fundo de vale, com até cerca de 26 mil anos, passa a ocorrer o predomínio da formação de planícies embutidas nos N1.

Ao longo do Holoceno, o encouraçamento das calhas verificado na região é um elemento importante para explicar a posição das bases das PI sob a lâmina d'água, bem como o recobrimento dos N1 por sedimentos recentes. A redução e/ou interrupção da incisão fluvial ocorrido na DG pode ter favorecido o encouraçamento dos canais e o aumento da sinuosidade, refletindo em uma redução ainda maior da capacidade e competência dos cursos d'água.

O encouraçamento das calhas e o recobrimento dos depósitos de N1 se destacam principalmente nos vales do Chiqueiro e do Rio Grande e devem estar relacionados às alterações da dinâmica hidrossedimentar já citadas na região. O recobrimento dos N1 já foi citado por Carvalho et al. (2018), Oliveira (2017), Santos, Rezende e Diniz (2010), Bueno, Trindade e Magalhães Junior (1997) e Saadi e Valadão (1987). O encouraçamento das calhas foi estudado por Cota, Magalhães Junior e Barros (2018) e Messias e Magalhães Junior (2014).

Na DG, o recobrimento dos depósitos de N1 pode ter relação com diversos fatores. É possível que o N1 corresponda a um nível de planície de inundação em abandono, que ainda recebe sedimentos durante chuvas com maior período de recorrência. Assim, o patamar mais baixo seria a planície atual em construção, direta e permanentemente influenciada pela dinâmica fluvial atual. O patamar mais elevado e mais espesso, embora ainda receba sedimentos com alguma regularidade, deve ser mais afetado pelos processos erosivos do que pelos deposicionais. O gradual abandono do nível superior deve estar associado à redução das vazões no Holoceno, ou à incisão fluvial em certos segmentos.

Há estudos que indicam que, a partir de 3.100 anos, ocorreu o estabelecimento de condições climáticas subúmidas, como as atuais, com pequenas variações nos últimos 740 anos (HORÁK-TERRA et al., 2020). Schellekens et al. (2014) sugerem que as condições climáticas se tornaram muito úmidas entre $~ 1.000$ e $~ 400$ anos. De forma complementar, Horák-Terra et al. (2015; 2011) afirmam que entre 1.100 e 400 anos as condições climáticas subúmidas favoreceram o acúmulo de matéria orgânica. Desse modo, pode-se considerar a possibilidade de o umedecimento do clima e aumento das chuvas nos últimos 1.600 anos, podendo ter provocado o aumento da vazão fluvial e inundações mais frequentes e/ou intensas para além das planícies de inundação então existentes (patamares inferiores). Nos últimos 300 anos, o aumento da umidade e a redução da cobertura vegetal, em um contexto de solos rasos e rochas pouco permeáveis, pode ter representado o ambiente propício para a intensificação dos eventos de inundação, devido à ampliação do escoamento superficial. Nessas condições, o transbordamento dos cursos d'água se tornaria mais recorrente e com volume de água capaz de ocupar os patamares mais elevados dos N1.

O recobrimento dos N1 pode ter sido reflexo do encouraçamento das calhas fluviais. Bridge (2003) afirma que o encouraçamento de leitos fluviais (bed armoring) é caracterizado pela presença de sedimentos imóveis ou imediatamente imóveis nas calhas, impedindo o transporte dos sedimentos potencialmente transportáveis. Os sedimentos imóveis formariam um pavimento detrítico que imporia resistência à abrasão, permitindo que somente os grãos nas frações de areia e de finos que recobrem o pavimento sejam transportados (FRINGS, 2008; CHARLTON, 2008; GRANT, 2012). Burbank e Anderson (2011) complementam que o entalhe da rocha subjacente ou o rebaixamento do nível de base pode se tornar mais lento ou cessar, caso a quantidade de sedimentos provenientes das vertentes seja maior que a capacidade de transporte fluvial. Assim, o encouraçamento forma uma barreira à incisão e ao encaixamento, facilitando o entulhamento e a elevação relativa da posição da lâmina d'água. Com o freio à incisão, o curso d'água concentra sua energia na migração lateral. Isso facilita a ocorrência de inundações que podem atingir níveis mais elevados nas margens. As inundações poderiam ser ainda mais 
potencializadas em contextos de aumento da precipitação e/ou de alterações antrópicas que favoreceriam o aumento do escoamento superficial e das vazões.

Diversos autores destacam o papel da evolução das voçorocas na DG para a disponibilização de sedimentos aos cursos d'água, conferindo o recrudescimento dos processos erosivos à atividade antrópica (AUGUSTIN; FONSECA; ROCHA, 2011). A ocupação humana deve ter contribuído com o encouraçamento devido ao maior aporte de sedimentos. Isso não significa que ela seja, necessariamente, a responsável pela gênese desse processo. O encouraçamento pode ser reflexo do aumento da carga sedimentar, principalmente de seixos, ou da perda de capacidade e competência fluvial em um período anterior à ocupação humana. Portanto, o aumento da carga sedimentar pode estar associado à uma oscilação climática ao longo do Quaternário. Como a vegetação não responde imediatamente a uma alteração das condições de umidade e temperatura, em um período de transição entre um clima mais seco e um mais úmido, o solo pode ter ficado desprotegido temporariamente e os processos erosivos atuando de forma mais intensa. A gênese do encouraçamento pode ser resposta a uma fase transicional. Assim, o aumento da umidade pode ter ocorrido de forma mais acelerada que a expansão da vegetação e as maiores taxas de erosão podem ter sido uma resposta ao aumento das precipitações.

A composição granulométrica das fácies de diversos N1, com destaque para a basal, indica condições de energia diferentes das atuais. As fácies de seixos que preenchem as calhas atuais indicam condições de energia muito diferentes das atuais, em que vários cursos d'água só remobilizam e transportam os sedimentos arenosos ou mais finos, como se observa no Rio Grande, Tigre, Chiqueiro, Areia e Datas. Como destaca Bueno, Trindade e Magalhães Junior (1997), os seixos e matacões são pouco afetados pelo trabalho fluvial atual na região.

O encouraçamento também pode estar associado à atual fase de estabilização do nível de base regional, evidenciado pela regularização de grande parte dos médios e baixos cursos. Isso ocorre no Chiqueiro e no Rio Grande. Este cenário pode estar relacionado à última fase de incisão fluvial, que rebaixou a calha ao nível atual e desestabilizou as encostas, refletindo na intensificação dos processos erosivos, conforme Augustin (2009) e Saadi (1995). A estabilização do nível de base e a regularização do canal, que reduziu sua declividade, podem ter refletido no aumento da sinuosidade, com os cursos fluviais iniciando um processo de meandramento. Assim, os canais passariam a migrar lateralmente e retirar somente os sedimentos mais finos, deixando clastos das fácies basais dos N1 e N2 nas calhas, como relata Bueno, Trindade e Magalhães Junior (1997). Esse contexto pode ser sido gerado pelo mencionado processo de encouraçamento das calhas, quando o acúmulo de seixos tornaria ainda mais intenso o processo de migração lateral e aumento da sinuosidade fluvial. Os seixos e matacões que não são remobilizados após a retirada das fácies superiores atuam como soleiras detríticas.

Considerando que o encouraçamento altera a estabilidade do sistema fluvial e o equilíbrio hidrossedimentológico, novas relações entre produção, transporte e sedimentação passam a vigorar, influenciando e modificando a geometria do canal, a vazão e o transporte de sedimentos. Consequentemente, o canal passaria a migrar lateralmente, erodindo suas margens e ampliando sua largura (VERICAT; BATALLA; GARCIA, 2006; SANTOS, 2008). Cota, Magalhães Junior e Barros (2018) associaram a dinâmica fluvial do Rio Grande, que tende ao meandramento, ao encouraçamento resultante da pavimentação do leito por sedimentos grosseiros.

\subsection{Evolução dos vales fluviais}

O perfil longitudinal do Rio Grande se encontra bastante regularizado, sobretudo no médio e no baixo curso, o que deve contribuir para a acumulação de sedimentos. Supõe-se que grande parte dos cursos d'água da região não tem energia cinética suficiente para transformá-la em mecânica e transportar os clastos maiores. A sinuosidade de um canal pode ser compreendida como um fator controlador da velocidade do escoamento em locais de relevos planos, haja vista que em canais com pouca declividade a energia potencial da gravidade tem menor efeito (SPANGHERO; MELIANI; MENDES, 2015). Assim, a intensificação do assoreamento é mais um indício da redução da energia nos canais.

Nesse contexto, pode-se propor que o encouraçamento das calhas fluviais situadas na DG seria intensificado pelas baixas condições de energia, associadas à estabilidade do nível de base regional e à regularização dos perfis longitudinais. Essa proposição está de acordo com Lana (2004), que associa a sinuosidade dos canais à sua própria declividade.

No Congonhas, Datas (alto curso) e Areia, os níveis de PI apresentam suave encaixamento em relação aos N1. No alto curso do Datas, o encaixamento da PI no N1 tem relação com a incisão fluvial nos quartzitos das formações 
Sopa-Brumadinho e Galho do Miguel, condicionando o rebaixamento do nível de base local desse segmento. No Congonhas, o encaixamento de $4 \mathrm{~m}$ deve estar associado à maior lentidão do curso d'água para romper uma soleira litológica em seu médio curso, a oeste da sede de Congonhas do Norte, onde atravessa um trecho de quase $2 \mathrm{~km}$ em que afloram os quartzitos da Formação Sopa-Brumadinho. O nível de base local representado por essas rochas foi responsável pela formação do N1 presente apenas no médio/alto curso do Ribeirão. Atualmente, após efetivar a incisão e regularizar o seu perfil longitudinal, alcançando o nível de base regional para o alto curso, ocorreu a formação da PI encaixada. No baixo curso, a PI encontra-se escalonada em relação ao N2, haja vista que a formação do $\mathrm{N} 1$ apenas no alto curso tem relação com o estabelecimento temporário do nível de base local. As idades obtidas corroboram com essa proposição, já que depósitos da PI e do N2 foram datados nos dois segmentos (D05 e D06 Tabela 2). No alto curso, a PI começou a ser formada há $170 \pm 170$ anos, enquanto a do baixo curso teve sua formação iniciada há $590 \pm 110$ anos. Já os N2, ambos localizados na vertente e com as bases a $15 \mathrm{~m}$ de distância vertical em relação à lâmina d'água, apresentam idades muito próximas $-5.600 \pm 630$ anos e $5.790 \pm 810$ anos.

Com relação ao suave encaixamento do nível de PI no N1 do vale do Areia, seria possível associá-lo a um rebaixamento do nível de base regional, representado pelo Rio Paraúna, que teria gerado um nível de base local temporário sustentado pelas rochas metabásicas. Verifica-se que o Areia atravessa as rochas metabásicas (metadiabásios e metagabros) em seu baixo curso, que pode atuar como níveis de base locais em segmentos fluviais. No Chiqueiro e no Rio Grande, em segmentos onde essas rochas afloram, é nítido o controle exercido por elas sobre a dinâmica fluvial, representando pequenos, mas verdadeiros níveis de base locais. As datações evidenciam a idade mais recente da PI do Areia (390 \pm 55 anos - D21, Tabela 2) em relação à PI do Rio Grande (630 \pm 80 anos - D17, Tabela 2). Isso corrobora com a proposição de uma incisão fluvial mais lenta no Areia. O suave encaixamento do Areia pode ser interpretado, de forma mais assertiva, como o resultado da regularização mais lenta do seu perfil longitudinal decorrente do avanço do último pulso de erosão remontante originado no rio Paraúna.

Os níveis de terraços nos fundos de vale complementam a interpretação acerca da evolução holocênica dos vales investigados. No vale do Chiqueiro, o N1 está embutido no N2, que por sua vez está escalonado em relação ao N3 em média vertente. No vale do Rio Grande, o N1 encaixou 0,3 m em relação ao N2, o qual se encontra escalonado em relação ao N3 em média vertente. Considerando que a formação dos N2 foi iniciada há $3.000 \pm 490$ anos no Chiqueiro e há $3.000 \pm 390$ anos no Rio Grande (D15 e D20, respectivamente - Tabela 2), e que ambos têm a sua base praticamente no mesmo nível da lâmina d'água atual, infere-se que as idades obtidas para as bases marcam bem o período em que ocorreu a estabilização do nível de base nos respectivos vales. Houve, como consequência, alterações na dinâmica hidrossedimentar que provocaram a diminuição da granulometria dos sedimentos transportados e a redução da espessura dos pacotes sedimentares.

No Datas (alto curso), Rio Grande e Sepultura, os N1 estão suavemente encaixados em relação aos respectivos N2. No Datas, o encaixamento corresponde a uma incisão de $3 \mathrm{~m}$, enquanto no Rio Grande o aprofundamento foi de somente $0,3 \mathrm{~m}$. De acordo com a datação da base do N2 do Rio Grande, o seu encaixamento iniciou há, pelo menos, $3.000 \pm 390$ anos. O encaixamento associado a esses níveis deve corresponder a um pulso de erosão remontante originado pelo rebaixamento do nível de base no Rio Paraúna, que se propagou pelo Chiqueiro e alcançou seus afluentes. No Datas (baixo curso) e no Rio Grande, a propagação ocorreu de forma mais lenta devido ao controle litológico, marcados pela presença de rochas metabásicas (córrego Rio Grande) e de rochas metafélsicas/metassedimentares (ribeirão Datas). Essas litologias devem ter atuado como níveis de base locais por determinado período, nos mesmos moldes do que ocorreu no Areia em relação à incisão observada entre os seus níveis PI e N1.

No Sepultura, o desnível do N1 em relação ao N2 varia ao longo do vale. No baixo curso, atinge $5 \mathrm{~m}$, enquanto no médio curso não ultrapassa $2 \mathrm{~m}$. É possível que, desde a formação do N2, iniciada há $26.350 \pm 4.470$ anos (D13 - Tabela 2), houve o soerguimento suave da parte em que se localiza o baixo curso, refletindo-se nessa diferença na intensidade da incisão. No entanto, não há indícios de movimentações de pequenos blocos que afetaram somente o baixo curso. Contudo, o mais plausível é considerar que, durante a formação do N2, a regularização do perfil longitudinal, compreendida como a redução da declividade em razão da estabilização do nível de base, foi intensa e que atualmente, este processo ocorre lentamente porque já não há tanta energia disponível. Provavelmente, o pulso de erosão remontante atuou com mais intensidade no baixo curso e perdeu força ao se propagar para montante.

O escalonamento do N1 em relação ao N2 foi verificado nos vales do Paraúna, Palmital, Areias, Datas (alto curso) e Tigre, com encaixamentos de 7, 4, 9 e 5 metros, respectivamente. No Datas (alto curso) e Palmital eles 
decorrem da alteração de níveis de base locais, controlados por quartzitos do Supergrupo Espinhaço. A formação do N1 do Palmital se iniciou há $2.320 \pm 430$ anos, (D09 - Tabela 2) indicando a estabilidade do nível de base desde então. No Datas (alto curso), a retomada da incisão fluvial ocorreu nos últimos $900 \pm 120$ anos, conforme idade da PI (D23 - Tabela 2).

O escalonamento entre os níveis mais antigos em fundos de vale e os mais recentes em contexto de vertente pode ser observado na relação entre a PI e o N1 do Congonhas, o N1 e o N2 do Palmital, o N1 e o N2 do Paraúna, o N1 e o N2 do Tigre, o N2 e o N3 do Sepultura, o N1 e o N2 do Areia, o N1 e o N2 do Datas (alto curso), o N2 e o N3 do Chiqueiro e o N2 e o N3 do Rio Grande. Esses escalonamentos representaram aprofundamentos da drenagem que variaram entre 3 e $15 \mathrm{~m}$. Devido às diferenças de intensidade de incisão entre esses níveis em contexto de fundo de vale e de vertente é possível que eles indiquem a existência de níveis de base locais diferentes para cada vale ou ainda que, mesmo sendo condicionados por um nível de base regional, o ritmo de rebaixamento ocorreu com intensidades distintas.

A existência de níveis de base locais anteriores à atual fase deposicional pode ser explicada pela diferença de resistência das litologias aos processos denudacionais (geoquímicos e mecânicos) ou ainda por uma dinâmica de blocos diferencial, que poderia ter provocado soerguimentos distintos para cada vale/bacia/conjunto de bacias. Assim, ao menos para os vales situados na DG, os soerguimentos com intensidades diferentes teriam sido suplantados pelo estabelecimento de um nível de base regional no Holoceno. Os cursos d'água que fluem sobre quartzitos e outras rochas resistentes do Supergrupo Espinhaço podem ainda estar respondendo aos últimos rebaixamentos de níveis de base ou pulsos neotectônicos, porém de forma mais lenta, devido ao controle litológico.

O arcabouço litoestrutural da região é fortemente marcado por falhas de empurrão, que poderia ter sido reativadas ao longo do Pleistoceno e Holoceno. Também é possível que a diferença de resistência das rochas ante aos processos denudacionais seja a responsável pelas variações de desníveis entre níveis deposicionais. Contudo, o input de energia associado aos soerguimentos pode estar sendo relativamente anulado em algumas partes do interior da SEM. Em alguns casos, como na bacia do Chiqueiro, isso estaria relacionado ao nível de base regional representado pelo rio Paraúna. Assim, mesmo que a área seja soerguida no conjunto da SEM, a manutenção do nível de base regional impede a propagação de pulsos de erosão remontante. Em outras bacias menores ou em áreas de borda, como a bacia do Contagem, o controle litológico exercido pelos quartzitos condicionaria e frearia a incisão fluvial, resultando em ritmos de incisões mais rápidas nos vales localizados próximos às bordas da Serra e mais lentas no interior.

A distribuição longitudinal e transversal dos níveis deposicionais ao longo dos vales é evidência importante da evolução geomorfológica regional. A partir dos registros locais, é possível discutir como a evolução dos vales foi condicionada pelo controle litoestrutural regional e como os cursos fluviais responderam, ao longo do tempo, às alterações dos níveis de base. Neste sentido, os níveis em contexto de vertente são indicativos importantes dos ciclos erosivo-deposicionais ocorridos em cada vale e, em conjunto, podem contribuir com a reconstituição geomorfológica em escala regional. A existência de até quatro desses níveis em alguns vales pode ser um indício importante das oscilações dos níveis de base.

Os registros mais significativos de rebaixamento de níveis de base foram identificados nos vales do Paraúna (N5, N4, N3 e N2), do Chiqueiro (N5, N4 e N3), do Tigre (N4, N3 e N2) e do Rio Grande (N5, N4 e N3). Esses processos podem estar associados aos pulsos neotectônicos sugeridos para a região. Contudo, os encaixamentos revelam incisões variadas, mas com predomínio de encaixamentos cada vez menos significativos em direção aos fundos dos vales, onde há indícios de sua estabilização devido a presença de níveis embutidos ou suavemente encaixados.

Nos registros deposicionais associados aos níveis de vertente predominam fácies grosseiras, com a preservação apenas de níveis basais de seixos. Isso decorre, principalmente, da remoção das fácies superiores por processos de erosão, desmontando a configuração original. A pouca preservação dos registros dificulta a sua integração nos modelos de interpretação geomorfológica regional. Neste sentido, não foi possível avançar nas discussões sobre os níveis mais antigos devido à pouca representatividade dos registros e à inexistência de fácies de finos passíveis de datação via LOE. 


\section{Conclusões}

Este estudo propõe a consideração de dois compartimentos geomorfológicos, a DG e as SE, nas quais as dinâmicas fluviais se comportam de formas distintas, devido às diferenças de intensidade da atuação de condicionantes geomorfológicos, como a litoestrutura, o clima e, em menor medida, a neotectônica. Os resultados e as discussões realizadas nesse trabalho sinalizam a importância dos cursos fluviais na configuração geomorfológicas, na bacia do Rio Paraúna, e nesses compartimentos que integram a SEM. Podem-se destacar os principais pontos:

- A evolução geomorfológica tem sido marcada pelos ritmos de alteração do nível de base regional (rio Paraúna) desde o Pleistoceno Superior, estabelecendo os marcos fisiográficos que foram aproveitados por processos naturais e antrópicos no Holoceno;

- A litoestrutura, a neotectônica e o clima tiveram papel de destaque no Pleistoceno Superior e no Holoceno. Contudo, no período mais recente do Holoceno, as atividades antrópicas estão intensificando os processos geomorfológicos e influenciando as características dos fundos de vales. A agricultura, a pecuária e a mineração podem ter intensificado os processos erosivos nas vertentes e condicionado a dinâmica hidrossedimentar, contribuindo com a intensificação do encouraçamento das calhas fluviais.

- A estabilização do nível de base regional (rio Paraúna) tem sido determinante para a configuração dos fundos de vales na DG: interrupção/redução da incisão fluvial, encouraçamento das calhas, regularização dos perfis longitudinais e o recobrimento de terraços em fundo de vale.

- O escalonamento de níveis deposicionais podem refletir o controle litoestrutura e, de modo secundário, à dinâmica neotectônica. A diferença de resistência entre as litologias que compõem a área e uma provável dinâmica diferencial de blocos podem ter condicionado as diferentes taxas de incisão fluvial observadas em cada vale.

- A estabilização do nível de base regional observado na DG favoreceu a gênese de fundos de vales com características mais homogêneas, enquanto as médias/altas vertentes preservaram diferentes números de níveis deposicionais, provavelmente refletindo ciclos de rebaixamento do nível de base decorrentes da dinâmica neotectônica e/ou do controle litoestrutural. Nas SE, as configurações dos vales fluviais apresentam diferenças que devem estar associadas às características litoestruturais locais, como a resistência aos processos denudacionais.

Contribuições dos Autores: Concepção, metodologia, elaboração de mapas, análise formal, pesquisa, recursos, preparação de dados, escrita do artigo, revisão: Alex de Carvalho; concepção, metodologia, análise formal, recursos, escrita do artigo, revisão, supervisão, aquisição de financiamento: Antônio Pereira Magalhães Junior. Todos os autores leram e concordaram com a versão publicada do manuscrito.

Agradecimentos: Os autores agradecem ao CNPq pela Bolsa Produtividade em Pesquisa do segundo autor.

Conflito de Interesse: Os autores declaram não haver conflito de interesse.

\section{Referências}

1. ALKMIN, F. F.; PEDROSA-SOARES, A. C.; NOCE, C. M., CRUZ, S. C. P. Sobre a evolução tectônica do orógeno AraçuaíCongo Ocidental. Geonomos, v. 15, n. 1, p. 25-43, 2007. DOI: 10.18285/geonomos.v15i1.105

2. ALMEIDA-ABREU, P. A. O Supergrupo Espinhaço da Serra do Espinhaço Meridional (Minas Gerais): o Rifte, a Bacia e o Orógeno. Geonomos, Belo Horizonte, v. 3, n. 1, p. 1-18, 1995. DOI: 10.18285/geonomos.v3i1.211

3. ALMEIDA-ABREU, P. A.; RENGER, F. E. Serra do Espinhaço Meridional: um orógeno de colisão do Mesoproterozóico. Revista Brasileira de Geociências, São Paulo, v. 32, n. 1, p. 1-14, 2002. DOI: 10.25249/0375-7536.20023210114

4. AUGUSTIN, C. H. R. R. Mudanças Climáticas no Pleistoceno Superior no Sudeste Brasileiro: resultados preliminares a partir de datações de C14. In: Congresso Argentino do Cuaternário y Geomorfologia, 4, Congresso da Associação Brasileira de Estudos do Quaternário, 12, Reunión sobre el Cuaternário de América del Sur, 2, 2009. Anais... 2009. p. 117-123.

5. AUGUSTIN, C. H. R. R.; FONSECA, B. M.; ROCHA, L. C. Mapeamento geomorfológico da Serra do Espinhaço Meridional: primeira aproximação. Geonomos, v. 19, n. 2, p. 50-69, 2011. DOI: 10.18285/geonomos.v19i2.41

6. ÁVILA, F. F.; CARVALHO, V. L. M. Morfogênese, pedogênese e etchplanação: análise integrada dos aspectos geoquímicos, mineralógicos e micromorfológicas dos solos de uma topossequência na Depressão de Gouveia - Serra do Espinhaço - Minas Gerais. Revista Brasileira de Geomorfologia, v. 13, n. 2, p. 223-233, 2012. DOI: 10.20502/rbg.v13i2.289 
7. BENITES, V. de M., CAIAFA, A. N., MENDONÇA, E. de S., SCHAEFER, C. E., KER, J. C. Solos e vegetação nos complexos rupestres de altitude da Mantiqueira e do Espinhaço. Floresta e Ambiente, v. 10, p. 76-85, 2003.

8. BENITES, V. de M., SCHAEFER, C. E. G. R., SIMAS, F. N. B., SANTOS, H. G. Soils associated with rock outcrops in the Brazilian mountain ranges Mantiqueira and Espinhaço. Revista Brasileira de Botânica, v. 30, n. 4, p. 569-577, 2007. DOI: 10.1590/s0100-84042007000400003

9. BRIDGE, J. S. Rivers and Floodplains. Blackwell Science, Oxford, 2003, 492p.

10. BUENO, G. T.; TRINDADE, E. S.; MAGALHÃES JUNIOR, A. P. Paleociclos deposicionais e a moderna dinâmica fluvial do ribeirão do Chiqueiro - Depressão de Gouveia/Espinhaço Meridional - MG. Geonomos, v. 5, n. 2, p. 15-19, 1997. DOI: 10.18285/geonomos.v5i2.177

11. BURBANK D. W.; ANDERSON R. S. Tectonic Geomorphology. John Wiley \& Sons, 2011, 454p.

12. CARVALHO, A.; MAGALHÃES JUNIOR., A. P.; FILIZZOLA, B. R.; MARQUES, C. P. M. O papel dos processos fluviais na configuração de fundos de vale na bacia do rio Paraúna - Serra do Espinhaço Meridional, Sudeste do Brasil. Revista Brasileira de Geomorfologia, v. 19, n. 4, p. 691-708, 2018. DOI: 10.20502/rbg.v19i4.1354

13. CHARLTON, R. Fundamentals of fluvial geomorphology. Londres; Routledge, 2008, 234p.

14. CHRISTOFOLETTI, A. Geomorfologia. São Paulo: Edgard Blücher, 1980, 186p.

15. CORDEIRO, J. S.; KNAUER, L. G.; COSTA, R. D.; PIUZANA, D.; MAGALHÃES, J. T. R. A análise da deformação finita em rochas metassedimentares da região da Serra da Matriculada, município de Datas (MG), Serra do Espinhaço Meridional. Geonomos, v. 6, n. 1, p. 1-10, 2008. DOI: 10.18285/geonomos.v16i1.88

16. CORRÊA, A. C. B.; SILVA, D. G. DA; MELLO, J.S. Utilização dos depósitos de encostas dos brejos pernambucanos como marcadores paleoclimáticos do Quaternário Tardio no semiárido nordestino. Mercator, v. 7, p. 99-125, 2008.

17. COTA, G. E. M.; MAGALHÃES JUNIOR., A. P.; BARROS, L. F. P. Processos de encouraçamento de leitos fluviais: sistematização de bases teóricas e estudo de caso na Serra do Espinhaço Meridional (MG). Revista Brasileira de Geomorfologia, v. 19, n. 4, p. 777-791, 2018. DOI: 10.20502/rbg.v19i4.1437

18. CRUZ, L. O. M.; VALADÃO, R. C.; MENEZES, M. L. N.; CARVALHO, V. L. M. Morfopedogênese em solos desenvolvidos em unidades coluviais na Depressão de Gouveia/MG. In: Simpósio Nacional de Geomorfologia (SINAGEO), 6, 2006, Goiânia. Anais... Goiânia. 2006.

19. FRINGS, R. M. Downstream fining in large sand-bed rivers. Earth-Science Reviews, v. 87, p. 39-60, 2008. DOI: 10.1016/j.earscirev.2007.10.001

20. GOREN, L.; WILLETT, S. D.; HERMAN, F.; BRAUN, J. Coupled numerical-analytical approach to landscape evolution modeling. Earth Surface Processes and Landforms, v. 39, n. 4, p. 522-545, 2014. DOI: 10.1002/esp.3514

21. GRANT, G. E. The geomorphic response of gravel-bed rivers to dams: perspectives and prospects. In: $\mathrm{CHURCH}, \mathrm{M}$; BIRON, P. M.; ROY, A. G. (org.). Gravel-Bed Rivers: Processes, Tools, Environments. Chichester: Wiley, 2012 , p. 165-181.

22. GROSSI-SAD, J. H.; LOBATO, L. M.; PEDROSA-SOARES, A. C.; SOARES-FILHO, B. S. (coordenadores e editores). Projeto Espinhaço em CD-ROM (textos, mapas e anexos). Belo Horizonte: COMIG - Companhia Mineradora de Minas Gerais. 1997.

23. GUEDES, C. C. F.; SAWAKUCHI, A. O.; GIANNINI, P. C. F.; DEWITT, R.; AGUIAR, V. A. P. Luminescence characteristics of quartz from Brazilian sediments and constraints for OSL dating. Anais da Academia Brasileira de Ciências, v. 85, n. 4, p. 1303-1316, 2013. DOI: 10.1590/0001-37652013104912

24. HACK, J. T. Interpretation of erosional topography in humid temperate regions. American Journal of Science, v. 258-A, p. 80-97, 1960.

25. HASBARGEN, L. E.; PAOLA, C. Landscape instability in an experimental drainage basin. Geology, v. 28, p. 1067-1070, 2000. DOI: 10.1130/0091-7613(2000)28<1067:liiaed $>2.0 . c 0 ; 2$

26. HORÁK, I., VIDAL-TORRADO, P., SILVA, A.C., PESSENDA, L. C. R. Pedological and isotopic relations of a highland tropical peatland, Mountain Range of the Espinhaço Meridional (Brazil). Revista Brasileira de Ciência do Solo, v. 35, n. 1, p. 41-52, 2011. DOI: 10.1590/s0100-06832011000100004

27. HORÁK-TERRA, I.; CORTIZAS, A. M.; LUZ, C. F. P.; LÓPEZ, P. R.; SILVA, A. C.; VIDAL-TORRADO, P. Holocene climate change in central-eastern Brazil reconstructed using pollen and geochemical records of Pau de Fruta mire (Serra do Espinhaço Meridional, Minas Gerais). Palaeogeography, Palaeoclimatology, Palaeoecology, v. 437, p. 117-131, 2015. DOI: 10.1016/j.palaeo.2015.07.027

28. HORÁK-TERRA, I.; CORTIZAS, A. M.; LUZ, C. F. P.; SILVA, A. C.; MIGHALL, T.; CAMARGO, PLÍNIO B.; MENDONCA FILHO, C. V.; OLIVEIRA, P.; CRUZ, F.; VIDAL-TORRADO, P. Late Quaternary vegetation and climate dynamics in centraleastern Brazil: insights from a $\sim 35 \mathrm{k}$ cal a BP peat record in the Cerrado biome. Journal of Quaternary Science, v. 35, p. 664-676, 2020. DOI: $10.1002 /$ jqs.3209

29. KNAUER, L. G. O Supergrupo Espinhaço em Minas Gerais: considerações sobre sua estratigrafia e seu arranjo estrutural. Geonomos, v. 15, n. 1, p. 81-90, 2007. DOI: 10.18285/geonomos.v15i1.109 
30. MAGALHÃES JUNIOR. A. P. Evolução da dinâmica fluvial cenozóica do Alto-médio Rio das Velhas na região de Belo Horizonte - MG. Dissertação (Mestrado em Geografia) - Programa de Pós-Graduação em Geografia, Universidade Federal de Minas Gerais, Belo Horizonte. 1993. 159p.

31. MAGALHÃES JUNIOR., A. P.; SOUZA, C. J. O.; MARQUES, M. R.; MOURA, M. T. T.; MOREIRA, P. F.; SILVEIRA, J. S.; VALADÃO, R. C. Modificações no padrão de sedimentação fluvial durante o Quaternário Tardio no Espinhaço Meridional. In: Congresso Brasileiro de Geologia, 37, 1992, São Paulo. Anais... São Paulo. 1992. p. 306-307.

32. MAGALHÃES JUNIOR, A. P.; BARROS, L. F. P. Depósitos Fluviais e feições deposicionais. In: MAGALHÃES JUNIOR, A. P.; BARROS, L. F. P. Hidrogeomorfologia: formas, processos e registros sedimentares fluviais. Rio de Janeiro: Bertrand Brasil, 2020, p. 260-278.

33. MAIA, L. P.; GASTÃO, F. G. C.; TATUMI, S. H.; LACERDA, L. D. A. Utilização do Método de Luminescência Opticamente Estimulada para a Datação de Sedimentos de Dunas Costeiras do Nordeste Setentrional do Brasil. Revista Virtual Química, v. 3, n. 2, p. 103-115, 2011. DOI: 10.5935/1984-6835.20110015

34. MENEZES, M. L. N.; CARVALHO, V. L. M.; CRUZ, L. O. M.; VALADÃO, R. C. Caracterização das formações superficiais em uma vertente do córrego do Quebra - Depressão de Gouveia/MG. In: Simpósio Nacional de Geomorfologia (SINAGEO), 6, 2006, Goiânia. Anais... Goiânia. 2006.

35. MESSIAS, R. M.; AMORIM, M. A. F.; AUGUSTIN, C. H. R. R.; AZEVEDO, P. A. A. Relação entre forma da vertente, cobertura superficial e sítios geomorfológicos na bacia do ribeirão do Chiqueiro, Depressão de Gouveia, Serra do Espinhaço Meridional - MG. Geonomos, v. 21, n. 2, p. 38-45, 2013. DOI: 10.18285/geonomos.v21i2.270

36. MESSIAS, R. M.; MAGALHÃES JUNIOR, A. P. Níveis deposicionais aluviais no vale do córrego do Rio Grande, Depressão de Gouveia - MG. In: Simpósio Nacional de Geomorfologia (SINAGEO), 10, 2014, Manaus. Anais... Manaus. 2014.

37. NEVES, S. C.; ALMEIDA-ABREU, P. A.; FRAGA, L. M. S. Fisiografia. In: SILVA, A. C.; PEDREIRA, L. C. V. S. F., ALMEIDA-ABREU, P. A. (Eds.). Serra do Espinhaço Meridional: Paisagens e Ambientes. Belo Horizonte: O Lutador, 2005, p. 47-58.

38. OLIVEIRA, G. S. Estudo de caso: reconstituição de eventos deposicionais fluviais em trecho do ribeirão do Chiqueiro, Gouveia - MG. In: Simpósio Brasileiro de Geografia Física Aplicada (SBGFA), 17, 2017, Campinas. Anais... Campinas. 2017. p. 3087-3097.

39. PEREIRA, M. G.; ANJOS, L. H. C.; VALLADARES, G. S. Organossolos: Ocorrência, gênese, classificação, alterações pelo uso agrícola e manejo. In: VIDAL-TORRADO, P.; ALLEONI, L. R. F.; COOPER, M.; SILVA, A.P. \& CARDOSO, E. J., eds. Tópicos em ciência do solo. Viçosa: Sociedade Brasileira de Ciência do Solo, v. 4, 2005, p. 233-276.

40. PONTEVEDRA-POMBAL, X.; MARTINEZ-CORTIZAS, A. Tuberas de Galicia: Processos formativos, distribuición y valor medioambiental. El caso particular de lãs "Serras Septentrionais". Chioglossa, v. 2, p. 103-121, 2004.

41. PRINCE, P. S.; SPOTILA, J. A.; HENIKA, W. S. Stream capture as driver of transient landscape evolution in a tectonically quiescent setting. Geology, v. 39, p. 823-826, 2011. DOI: 10.1130/g32008.1

42. REINHARDT, L.; ELLIS, M. A. The emergence of topographic steady state in a perpetually dynamic self-organized critical landscape. Water Resourses Research, v. 51, p. 4986-5003, 2015. DOI: 10.1002/2014wr016223

43. ROCHA, L. C.; AUGUSTIN, C. H. R. R.; FONSECA, B. M.; AULER, L. M. L. A.; FRANCO, M. B. Desnudação geoquímica e seu papel na modelagem do relevo da Serra do Espinhaço Meridional. Simpósio Nacional de Geomorfologia, 8, Encontro Latino-Americano de Geomorfologia, 3, Encontro Íbero Americano de Geomorfologia, 1, Encontro Íbero Americano do Quaternário, 1, 2010, Recife. Anais... Recife. 2010.

44. ROCHA, L. C.; AVILA, F. F.; FIGUEIREDO, A. C.; MAGAlHÃES JUNIOR. A. P.; SALGADO, A. A. R. Dinâmica Fluvial, Identificação e Caracterização de Terraços Fluviais no Médio Curso do Rio Paraúna, Gouveia - MG. In: VII Simpósio Nacional de Geomorfologia, 7, Encontro Latino-Americano de Geomorfologia, 2, 2008, Belo Horizonte. Dinâmica e Diversidade de Paisagens. Anais... Belo Horizonte: UFMG: 2008.

45. SAADI, A. A geomorfologia da Serra do Espinhaço em Minas Gerais e de suas margens. Geonomos, v. 3, n. 1, p. 41-63, 1995. DOI: 10.18285/geonomos.v3i1.215

46. SAADI, A.; VALADÃO, R. C. O Cenozoico da porção mediana-central do Espinhaço Meridional - 1ª Síntese. In: Congresso da Associação Brasileira de Estudos do Quaternário, 1, 1987, Porto Alegre. Anais... Porto Alegre: UFRGS/ABEQUA. 1987, p. 393-407.

47. SALLUN, A. E. M., SUGUIO, K.; TATUMI, S. H.; YEE, M.; SANTOS, J.; BARRETO, A. M. F. Datação absoluta de depósitos quaternários brasileiros por luminescência. Revista Brasileira de Geociências, v. 37, n. 2, p. 401-412, 2007. DOI: 10.25249/03757536.2007373402413

48. SANTOS, G. B. Geomorfologia Fluvial no Alto Vale do Rio das Velhas, Quadrilátero Ferrífero - MG: Paleoníveis Deposicionais e a Dinâmica erosiva e deposicional atual. Dissertação (Mestrado em Geografia), Programa de Pós-Graduação em Geografia, Universidade Federal de Minas Gerais, Belo Horizonte. 2008. 130p. 
49. SANTOS, T. A.; REZENDE, E. A.; DINIZ, R. F. Dinâmica fluvial quaternária do alto curso do Córrego Trombador, Gouveia - MG. Simpósio Nacional de Geomorfologia, 8, Encontro Latino-Americano de Geomorfologia, 3, Encontro Ibero-Americano de Geomorfologia, 1, Encontro Ibero-Americano do Quaternário, 1, 2010, Recife. Anais... Recife. 2010.

50. SCHELLEKENS, J.; HORÁK-TERRA, I.; BUURMAN, P.; VIDAL-TORRADO, P.; SILVA, A. C. Holocene vegetation and fire dynamics in central-eastern Brazil: Molecular records from the Pau de Fruta peatland. Organic Geochemistry, v. 77, p. 3242, 2014. DOI: 10.1016/j.orggeochem.2014.08.011

51. SILVA, A. C. Solos. In: SILVA, A.C., PEDREIRA, L. C. V. S. F., ALMEIDA-ABREU, P. A. (Eds.). Serra Do Espinhaço Meridional: Paisagens e Ambientes. Belo Horizonte: O Lutador, 2005, p. 61-77.

52. SILVA, A. C.; PEDREIRA, L. C. V. S. F.; ALMEIDA ABREU, P. A. Serra do Espinhaço Meridional: Paisagens e ambientes. Belo Horizonte: O Lutador, 2005, 272p.

53. SILVA, E. de B., SILVA, A. C., GRAZZIOTTI, P. H., FARNEZI, M. M. de M., FERREIRA, C. A., COSTA, H. A. O., HORAK, I. Comparação de métodos para estimar a acidez potencial mediante determinação do pH SMP em organossolos da Serra do Espinhaço Meridional. Revista Brasileira de Ciência do Solo, v. 32, p. 2007-2013, 2008. DOI: 10.1590/s0100-06832008000500022 54. SPANGHERO, P. E. S. F.; MELIANI, P. F.; MENDES, J. S. Mapeamento hidrográfico de detalhe e análise morfométrica comparativa das bacias dos rios Tijuípe e Tijuipinho, litoral sul da Bahia. Caminhos de Geografia, v. 16, n. 53, p. 101-117, 2015. 55. TORRES, F. T. P.; MARQUES NETO, R.; MENEZES, S. O. Introdução à Geomorfologia. São Paulo: Cengage Learning, 2012, 322p.

56. VALADÃO, R. C. Geodinâmica de superfícies de aplanamento, desnudação continental e tectônica ativa como condicionantes da megageomorfologia do Brasil Oriental. Revista Brasileira de Geomorfologia, v. 10, n. 2, p. 77-90, 2009. DOI: 10.20502/rbg.v10i2.132

57. VALADÃO, R. C.; SILVEIRA, J. S.; SIMÕES, P. M. L.; SANTOS, P. R. O.; OLIVEIRA, C. V.; CARVALHO, V. L. M.; AUGUSTIN, C. H. R. R. Geomorfogênese da borda de uma faixa móvel neoproterozóica: o atual Planalto do Espinho Meridional. In: Simpósio Nacional de Geomorfologia, 9, 2012, Rio de Janeiro. Anais... Rio de Janeiro: UFRJ. 2012.

58. VERICAT, D.; BATALLA, R. J.; GARCIA, C. Breakup and reestablishment of the armour layer in a large gravel-bed river below dams: The lower Ebro. Geomorphology, v. 76, p. 122- 136, 2006. DOI: 10.1016/j.geomorph.2005.10.005

59. WILLETT, S. D.; MCCOY, S. W.; PERRON, J. T.; GOREN, L.; CHEN, C. Y. Dynamic reorganization of river basins. Science, v. 343, n. 1248765, 2014. DOI: 10.1126/science.1248765

60. WINTLE, A. G.; MURRAY, A. S. A review of quartz optically stimulated luminescence characteristics and their relevance in single-aliquot regeneration dating protocols. Radiat Meas, v. 41, p. 369-391, 2006. DOI: 10.1016/j.radmeas.2005.11.001.

Esta obra está licenciada com uma Licença Creative Commons Atribuição 4.0 Internacional (http://creativecommons.org/licenses/by/4.0/) - CC BY. Esta licença permite que outros distribuam, remixem, adaptem e criem a partir do seu trabalho, mesmo para fins comerciais, desde que lhe atribuam o devido crédito pela criação original. 